\title{
A taxonomic and taphonomic study of Pleistocene fossil deposits from the western Nefud Desert, Saudi Arabia
}

\author{
Mathew Stewart ${ }^{\mathrm{a}, \mathrm{b} *}$ (D), Julien Louys ${ }^{\mathrm{c}}$, Paul S. Breeze ${ }^{\mathrm{d}}$, Richard Clark-Wilson ${ }^{\mathrm{e}}$, Nick A. Drake ${ }^{\mathrm{d}, \mathrm{f}}$, Eleanor M.L. Scerrif ${ }^{\mathrm{f}, \mathrm{g}}$,

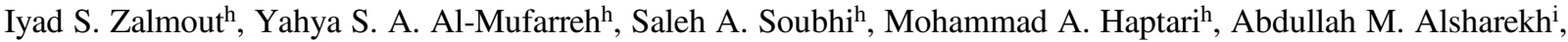 \\ Huw S. Groucutt ${ }^{\mathrm{a}, \mathrm{f}}$, Michael D. Petraglia ${ }^{\mathrm{f}, \mathrm{j}, \mathrm{k}}$ \\ ${ }^{a}$ Extreme Events Research Group, Max Planck Institute for Chemical Ecology, Hans-Knöll-Strasse 8, 07745 Jena, Germany \\ ${ }^{b}$ Palaeontology, Geobiology, and Earth Archives Research Centre, School of Biological, Earth and Environmental Science, University of New South Wales, \\ Sydney 2052, Australia \\ ${ }^{\mathrm{c}}$ Australian Research Centre for Human Evolution (ARCHE), Environmental Futures Research Institute, Griffith University, Nathan, Queensland 4111, \\ Australia \\ dDepartment of Geography, King's College London, London, UK \\ e'Department of Geography, Royal Holloway, University of London, UK \\ ${ }^{\mathrm{f}}$ Department of Archaeology, Max Planck Institute for the Science of Human History, Kahlaische Strasse 10, D-07743 Jena, Germany \\ ${ }^{\mathrm{g}}$ School of Archaeology, University of Oxford, 36 Beaumont Street, Oxford OX1 2PG, UK \\ ${ }^{\text {h}}$ Saudi Geological Survey, Palaeontology Department, Jeddah, Saudi Arabia \\ i Department of Archaeology, King Saud University, Riyadh, Saudi Arabia \\ ${ }^{\mathrm{j}}$ Human Origins Program, National Museum of Natural History, Smithsonian Institution, Washington, DC 20560, USA \\ ${ }^{\mathrm{k}}$ School of Social Science, University of Queensland, Brisbane, Queensland 4072, Australia \\ *Corresponding author e-mail address: mstewart@ice.mpg.de (M. Stewart).
}

(Received March 7, 2019; AcCePTED January 7, 2020)

\begin{abstract}
Over the past decade, a growing interest has developed on the archaeology, palaeontology, and palaeoenvironments of the Arabian Peninsula. It is now clear that hominins repeatedly dispersed into Arabia, notably during pluvial interglacial periods when much of the peninsula was characterised by a semiarid grassland environment. During the intervening glacial phases, however, grasslands were replaced with arid and hyperarid deserts. These millennial-scale climatic fluctuations have subjected bones and fossils to a dramatic suite of environmental conditions, affecting their fossilisation and preservation. Yet, as relatively few palaeontological assemblages have been reported from the Pleistocene of Arabia, our understanding of the preservational pathways that skeletal elements can take in these types of environments is lacking. Here, we report the first widespread taxonomic and taphonomic assessment of Arabian fossil deposits. Novel fossil fauna are described and overall the fauna are consistent with a well-watered semiarid grassland environment. Likewise, the taphonomic results suggest that bones were deposited under more humid conditions than present in the region today. However, fossils often exhibit significant attrition, obscuring and fragmenting most finds. These are likely tied to wind abrasion, insolation, and salt weathering following fossilisation and exhumation, processes particularly prevalent in desert environments.
\end{abstract}

Keywords: Arabian Peninsula; Desert; Taphonomy; Weathering; Wind abrasion; Insolation; Hippopotamus

\section{INTRODUCTION}

Throughout the Pleistocene the Arabian Peninsula underwent a series of pluvial phases that transformed much of its deserts into well-watered semiarid grasslands (Rosenberg et al., 2011, 2013; Drake et al., 2013; Breeze et al., 2015, 2016; Jennings et al., 2015; Parton et al., 2015, 2018;

Cite this article: Stewart, M. et al 2020. A taxonomic and taphonomic study of Pleistocene fossil deposits from the western Nefud Desert, Saudi Arabia. Quaternary Research 95, 1-22. https://doi.org/10.1017/qua.2020.6
Groucutt et al., 2015b, 2018; Roberts et al., 2018). These conditions facilitated the dispersal of a variety of novel taxa into Arabia, including hippos, elephants, large carnivores, and waterbirds (McClure, 1984; Thomas et al., 1998; Stimpson et al., 2016; Stewart et al., 2019a, 2019b; Groucutt et al., 2018). Hominins, too, appear to have repeatedly occupied Arabia during these more humid intervals, as indicated by the archaeological record (e.g., Petraglia et al., 2011, 2012; Groucutt and Petraglia, 2012; Shipton et al., 2014, 2018; Groucutt et al., 2015a, 2015b, 2018; Scerri et al., 2015). A recent fossil finding places Homo sapiens 
in the region by ca. $90 \mathrm{ka}$ (Groucutt et al., 2018) and recently discovered lithic artefacts demonstrate that hominins dispersed into Arabia as early as ca. 500-300 ka (Roberts et al., 2018; Stewart et al., 2019a).

Considering the importance of the Arabian Peninsula in hominin prehistory, and the regular occurrence of spatially associated lithic artefacts and fossils at relict lake and river sites within the Arabian interior (e.g., Delagnes et al., 2012; Scerri et al., 2015; Breeze et al., 2017; Groucutt et al., 2018; Roberts et al., 2018; Stewart et al., 2019a), it is crucial that we develop an understanding of the preservational pathways that skeletal elements in these environments might take. Fortunately, the need for taphonomic frameworks with which to study large vertebrate fossil assemblages has long been recognised and a wealth of actualistic and naturalistic landscape studies within tropical settings have been conducted and applied to questions surrounding hominin and animal landscape use, interactions, and behaviour (e.g., Behrensmeyer, 1978; Behrensmeyer and Dechant Boaz, 1980; Blumenchine, 1986, 1988, 1989; Domínguez-Rodrigo, 2001; Faith and Behrensmeyer, 2006; Faith, 2007). Considerably less attention, however, has been devoted to understanding the taphonomic processes operating in desert environments (e.g., Andrews and Whybrow, 2005; Denys et al., 2007). Deserts experience rapid sediment deflation and depositional hiatuses (Parton et al., 2018) that prolong deposition and facilitate the exhumation of fossils. Once on the surface, fossils in deserts are exposed to extreme temperature fluctuations, frost, strong winds, sandstorms, and rare but intense downpour events, all of which may serve to significantly modify fossil appearance and assemblage composition (Denys et al., 2007). The Nefud Desert is no exception. Extreme diurnal temperature variations cause rocks to fracture and exfoliate, winter temperatures reach below freezing, and strong winds occasionally incite severe sandstorms (Edgell, 2006). How these conditions might affect the preservation of fossils has not been systematically investigated.

Here we report a taxonomic and taphonomic assessment of ten Arabian Pleistocene fossil deposits (Fig. 1). Fossils include both surface and excavated specimens collected from the western Nefud Desert, northern Saudi Arabia. This study adds new taxa to the currently depauperate Arabian fossil record. It summarises the common taphonomic processes that dictated bone assemblage accumulation in Pleistocene Arabian palaeolake settings and reports on those that continue to modify fossil assemblages today.

\section{PREVIOUS INVESTIGATIONS}

The site of Khall Amayshan-1 (KAM-1, or "Thomas loc-1") has previously been investigated by various research teams (Thomas et al., 1998; Rosenberg et al., 2013; Scerri et al., 2015). The palaeolake sequence is elevated up to $2.5 \mathrm{~m}$ above the basin floor and comprises interdigitated marls, silts, and sands, indicating lake-level fluctuations throughout its existence (Rosenberg et al., 2013; Scerri et al., 2015). Diatoms are dominated by freshwater species and indicate a shallowing of the lake moving up the sequence (Rosenberg et al., 2013). Thomas and colleagues (1998) recovered fossils from the surface of the palaeolake and initially attributed the site to the early Pleistocene based on their interpretation of a mostly extinct faunal assemblage that included Pelorovis sp. cf. P. oldowayensis and tentatively attributed Hexaprotodon (Thomas et al., 1998). However, subsequent investigations of the site using optically stimulated luminescence (OSL) dating found the deposits directly beneath the fossils to range between $117 \pm 8 \mathrm{ka}$ and $99 \pm 7 \mathrm{ka}$ (Rosenberg et al., 2013). Rosenberg et al. (2013), in their stratigraphic log of the site (their fig. 12, p. 117), indicated that fossils were present in the uppermost marl unit $(\sim 30 \mathrm{~cm})$ and in the underlying calcareous sands $(\sim 50-60 \mathrm{~cm})$ but provided no details on the remains themselves. Scerri et al. (2015) also noted fossils scattered on the surface of the palaeolake deposit and reported 106 Middle Palaeolithic lithic artefacts. Artefacts were made of both local (quartzite) and nonlocal (chert) material and likely reflect several discrete flaking episodes, indicating the repeated use of the lake by late Pleistocene hominins.

A second site just north of KAM-1, called Khall Amayshan-4 (KAM-4), comprises six distinct palaeolake deposits-northwest (NW) lake, northeast (NE) lake, south (S) lake, southwest (SW) lake, southeast (SE) lake, and central lake (Fig. 2). Each palaeolake deposit was associated with a discrete lithic artefact assemblage ranging from Acheulean to Middle Palaeolithic, suggesting that lake formation at the site was not contemporaneous (Scerri et al., 2015). Abundant lithics, including some refits, indicate that some knapping took place on site (Scerri et al., 2015).

An additional site located a few kilometres northeast of KAM-4, called Site 16.3, was also investigated by Rosenberg et al. (2013; Fig. 3). The deposit consists of a $\sim 170$-cm-thick laminated white diatomite underlain by white sands dated by OSL to $99 \pm 7 \mathrm{ka}$. Rosenberg et al. $(2011,2013)$ found that the aeolian sediments underlying palaeolake deposits typically predated lake formation by only a few thousand years, suggesting lake onset at Site 16.3 lies close to $99 \mathrm{ka}$. Diatom analysis demonstrated an abundance of freshwater species and a gradual change toward a dominance of planktonic and facultatively planktonic taxa, indicating a transition to deeper waters moving up the sequence (Rosenberg et al., 2013).

\section{METHODS}

\section{Surveys}

The 2013-2016 surveys focused on palaeohydrological features (i.e., relict lakes, wetlands, and rivers) owing to their importance as palaeoenvironmental proxies and high potential to yield archaeological and palaeontological material, as demonstrated by previous research (e.g., Petraglia et al., 2012; Rosenberg et al., 2013; Scerri et al., 2015; Stimpson et al., 2015, 2016; Stewart et al., 2019a). Palaeolakes and wetlands were identified via remote sensing (see Breeze et al., $2015,2016,2017)$ and were investigated on both the fringe of the present-day dune field (via four-wheel-drive vehicles) 


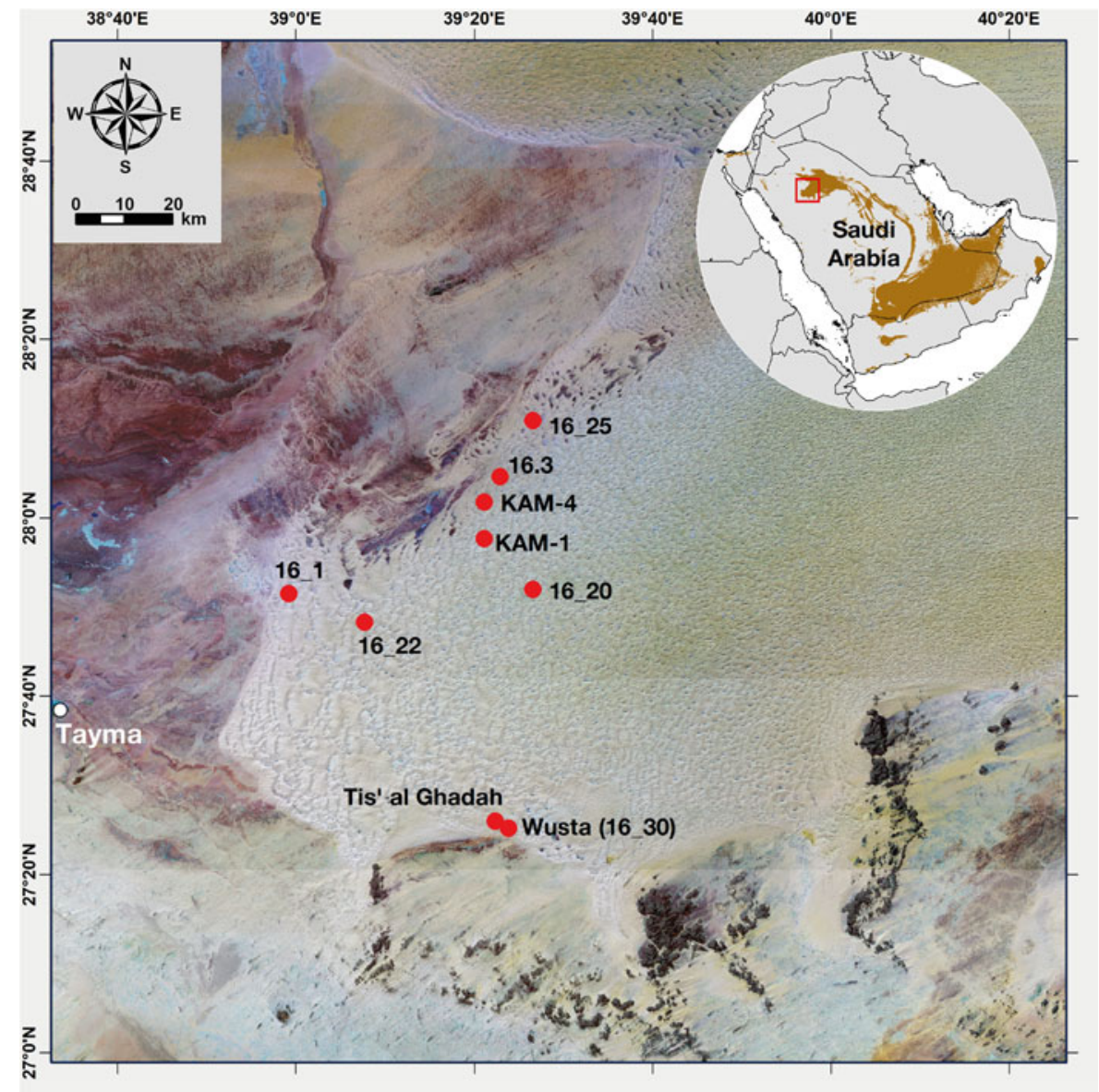

Figure 1. Map of fossil localities mentioned in the text (inset taken from Breeze et al., [2017]). Figure is a Landsat 5 false colour (bands 7, 4, 1, RGB) multispectral satellite image of the western Nefud. This band combination highlights the dunes of the sand sea in yellow, while bedrock exposures and the plains surrounding the Nefud are in darker tones. (For interpretation of the references to color in this figure legend, the reader is referred to the web version of this article.)

and deeper into the desert interior (via helicopter, provided the Saudi Geological Survey) (Fig. 1). A total of 40 sites were investigated, most of which yielded significant environmental archives, many with lithic artefacts, and some with fossils (for further details, see Breeze et al., 2017). Ten of the fossil-bearing deposits are reported in the present study. All sites reported here comprise inverted relief outcrops of ancient lake deposits situated in interdunal depressions within the western Nefud Desert, attesting to the significant sediment erosion and deflation of palaeolake sediments in the region. While direct chronological information is only available for KAM-1 and Site 16.3, it is likely that all the deposits date to the Pleistocene. Indeed, all dated palaeolake deposits in the western Nefud Desert can be tied to the humid periods of the middle and late Pleistocene.

At each location, pedestrian surveys were conducted across the extent of all exposed palaeolake surfaces, as well as part way up the sand dunes flanking these (for additional details, see Breeze et al., 2017). Given that each site comprised only a small area(s) of exposed palaeolake sediments isolated within interdunal depressions, site surveys were relatively quick and straightforward. Surveys were conducted by "fanning" out across the landscape. This assisted in locating all areas of exposed palaeolake sediments. All fossils, regardless of size, were plotted using a total station or differential global positioning systems (DGPS), given a unique identifier number, and collected. Given that most fossils are surface finds recovered from restricted areas atop palaeolake surfaces with which they can be parsimoniously associated, we treat each site as a single, distinct fossil assemblage but note that time-averaging and mixing may have occurred. Shallow excavations (using trowels and brushes) were conducted at two sites (Site 16.3, WNEF16_1) to recover dense concentrations of fossils that were found eroding out of the palaeolake surfaces. The discovery of fossils eroding out of the fringe of the KAM-4 NW lake deposit prompted the excavation of four $2 \times 2 \mathrm{~m}$ trenches (Fig. 2). Excavations focused on the palaeolake sediments, which extended to a depth of $\sim 120 \mathrm{~cm}$ before reaching the underlying sterile dune sands. All excavated sediment was sieved through a $2-\mathrm{mm}$ mesh, and all fossils were collected.

\section{Systematic palaeontology}

Each fossil specimen was identified to the lowest taxonomic level possible; this process was facilitated by osteological 

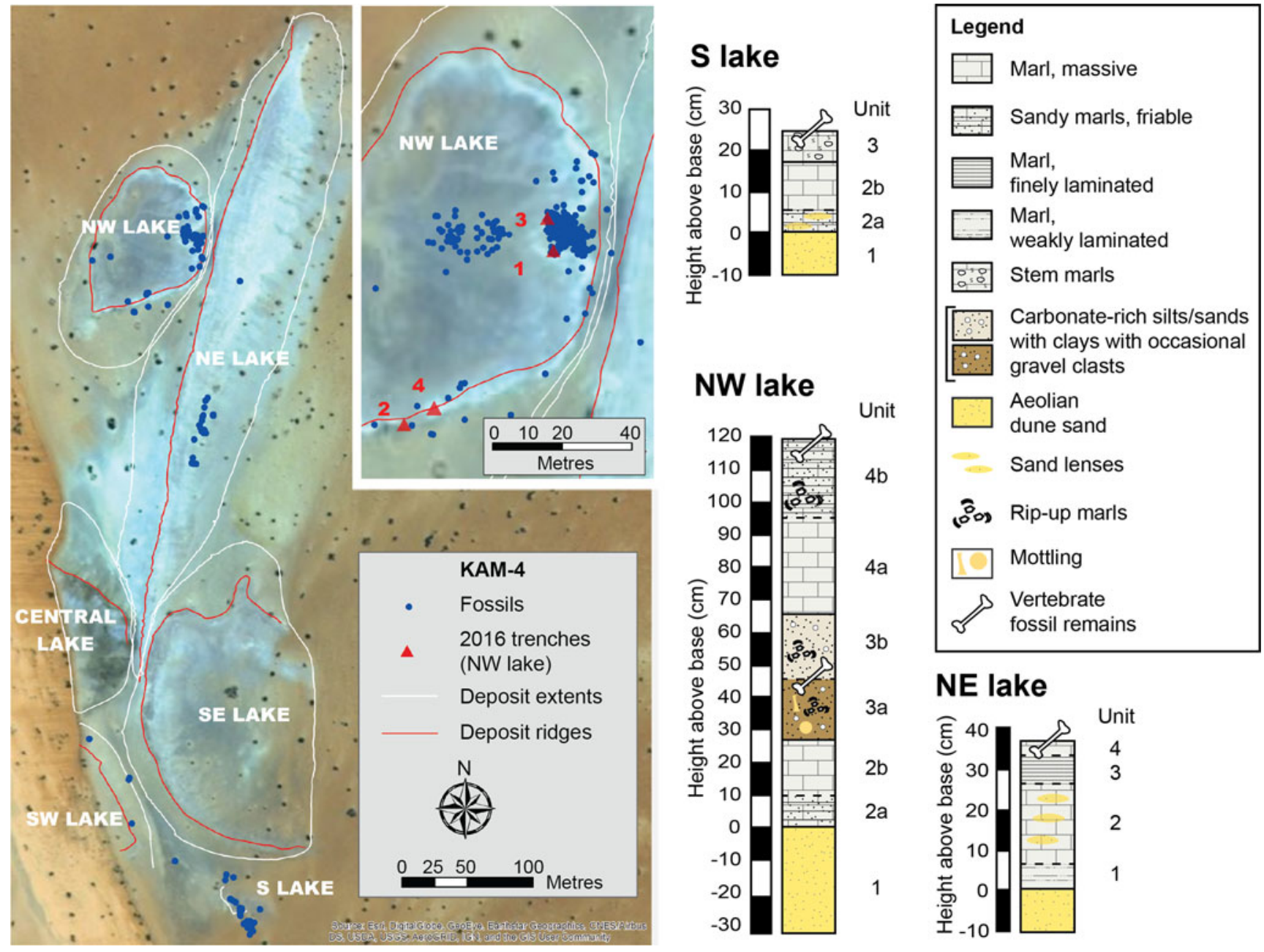

Figure 2. (color online) Map of KAM-4 showing the position of the different lakes and lake boundaries, trenches, and fossils (left), and full sedimentary sequence of the fossil-bearing deposits (right).

collections housed at the Australian National University (ANU) and University of New South Wales (UNSW), as well as by indirect comparisons (photographs, measurements) with material housed at the Smithsonian Institution National Museum of Natural History (NMNH), USA. Fossil dimensions (length, width) were measured using digital callipers and additional comparative morphometric data were collected following von den Driesch (1976).

\section{Taphonomic analysis}

Taphonomic analysis was conducted following established methods and fossils were investigated by eye, geological hand lens (10-20x), and light binocular microscope (up to 40x) (for a detailed discussion of the methods, see Stewart et al., 2019a). Specimen counts were reported in standard quantitative units: number of recovered specimens (NRSP), number of identified specimens (NISP), minimum number of elements (MNE), and minimum number of individuals (MNI). MNE was calculated as the minimum number of skeletal units needed to account for all specimens of a given skeletal unit without taking into consideration the age or side (for bilaterally paired elements) of the animal (Bunn and Kroll, 1986). MNI was calculated similarly but by taking into consideration age and side. Fossils were assigned an animal size class based on a simplified version of the size classes listed in Bunn (1982): small-sized animals (size classes I-II; $<100 \mathrm{~kg}$; e.g., gazelle), medium-sized animals (size class III; 100-340 kg; e.g., wildebeest), and large-sized animals (size classes IV-VI; $>340 \mathrm{~kg}$; e.g., elephant).

Each fossil was assigned a weathering stage ranging from zero (unweathered) to five (extensively weathered) following Behrensmeyer (1978). Fossils were also assessed for root etching, manganese staining, and sediment abrasion, although their precise frequencies were not always quantified. Root etching was defined as irregular U-shaped grooves, often occurring in dense concentrations, and are the result of the dissolution of bone tissue by plant root chemicals (Fernández-Jalvo and Andrews, 2016). Manganese staining was defined as the blackening of bone, often appearing patchy and spatially confined, and is typically the product of deposition in water or water-lain sediments but may also arise from dry bacterial growth (Fernández-Jalvo and Andrews, 2016). Sediment abrasion was defined as the rounding, pitting, and 

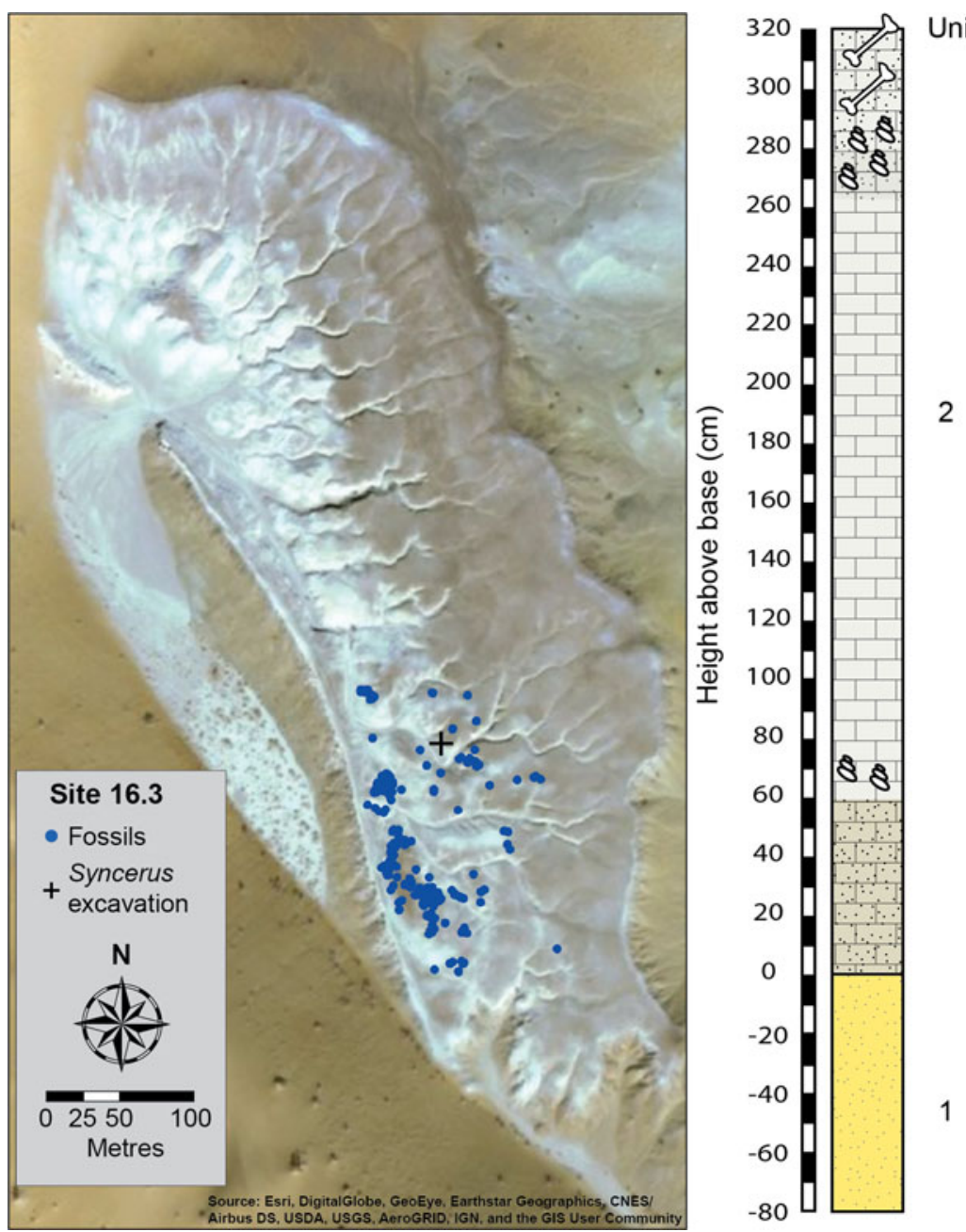

Figure 3. (color online) Map of Site 16.3 showing the location of the lithics, fossils, and Syncerus skeleton (left), and full stratigraphic log (right).

polishing of fossils and the cause of abrasion (e.g., windblown sediment, water-sediment abrasion, trampling) was distinguished based on criteria outlined in the literature (e.g., Olsen and Shipman, 1988; Fernández-Jalvo and Andrews, 2003; Denys et al., 2007). Carnivore tooth marks were identified as pits, scores, furrows, and punctures following Binford (1981), and tooth pit dimensions were recorded following Domínguez-Rodrigo and Piqueras (2003).

Long-bone circumference completeness (\%) was recorded as type 1 (less than half), type 2 (more than half but incomplete), or type 3 (complete) following Bunn (1982). Longbone breakage was recorded as green (fresh) or dry based on the fracture angle, outline, and edge characteristics described in Villa and Mahieu (1991). When suitable, density-mediated attrition was investigated by Spearman's rank-order correlation coefficient between MNE and wildebeest bone mineral density (Lam et al., 1999). To investigate preferential fluvial transport of bones, fossils were placed into categories based on Voorhies transport groups (Voorhies, 1969). Additionally, the tooth to vertebrate ratio $(T / V)$ was also calculated as a measure of hydraulic winnowing, with values between $0.44-1.5$ and $3.12-3.48$ indicating limited and strong hydraulic winnowing, respectively (following Behrensmeyer, 1975). Statistical analyses were carried out in PAST (Hammer et al., 2001), and graphics were generated using RStudio (RStudio Team, 2015).

\section{RESULTS}

\section{Systematic Palaeontology}

Order Testudines Batsch, 1788

Testudines sp.

Material: Site 16.3 - two plastron fragments (16.3/255, 256) and a single vertebra (16.3/405); WNEF16_20 - three carapace fragments (unnumbered).

Description: Two small tortoise plastron fragments, between $4 \mathrm{~mm}$ and $6 \mathrm{~mm}$ in thickness, and three carapace fragments. A single, poorly preserved vertebrae with maximum length and width of $27.7 \mathrm{~mm}$ and $21.4 \mathrm{~mm}$, respectively, is also likely that of a tortoise. Given the 
fragmentary nature of these specimens, little more can be said regarding their taxonomy.

\section{Class Aves Linnaeus, 1758}

Referred material: Site 16.3 - coracoid bone (16.3/259); KAM-4 NW lake - a humerus (KAM4/1), proximal femur (unnumbered), distal tarsometatarsus (unnumbered), metapodial (KAM4/294), distal second metacarpal (unnumbered), and two distal phalanges (KAM16/301 and unnumbered).

Remarks: Various small bird bones were recovered, but all are fragmented and provide no further diagnostic characteristics.

Order Stuthioniformes Latham, 1790

Family Struthionidae Vigors, 1825

Genus Struthio Linnaeus, 1758

Struthio sp.

Material: KAM-4 S lake - a single eggshell fragment (unnumbered); KAM-4 NW lake - two egg shell fragments (KAM16/547, unnumbered).

Description and remarks: Thick eggshell fragments with a mostly smooth surface and pores tightly concentrated in shallow circular to semicircular pits are referred to ostrich eggshell (Fig. 4C). Shell thickness measured $\sim 2.0 \mathrm{~mm}$ and pit diameter measured between $0.5 \mathrm{~mm}$ and $0.75 \mathrm{~mm}$, consistent with late Pleistocene ostrich eggshell recovered from sites in Asia (Shani et al., 1989; Blinkhorn et al., 2015) and Africa (Texier et al., 2013).

Class Mammalia

Order Rodentia Bowdich, 1821

Family Muridae Illiger, 1811

Muridae gen. et sp. indet.

Material: KAM-4 NW lake - left mandible with $\mathrm{m} 2$ and $\mathrm{m} 3$ in place (KAM-4/290).

Description and remarks: Teeth are rooted, brachydont, heavily worn, and exhibit a simple occlusal pattern (Fig. 4B). The $\mathrm{m} 3$ has a triangular occlusal outline that is narrower to the posterior, whereas the $\mathrm{m} 2$ is square and with two buccolingually arranged lophs. The preserved tooth-row length is $4.9 \mathrm{~mm}$, and the complete tooth row length $(\mathrm{m} 2-\mathrm{m} 3)$ is estimated to be $7.3 \mathrm{~mm}$. Dipodidae can be discounted based on either their more complex occlusal pattern and/or small size, and in the case of Paradipus by the presence of enamel on the molar buccal and lingual surfaces. Overall, the molar shape and cusp disposition is typical of that of murids. Muridae is a diverse and widespread family of rodents and species of Apodemus, Arvicanthus, Acomys, Rattus, Mus, Nesokia, among others, can be found in Arabia today (Harrison and Bates, 1991), while earlier murid taxa (e.g., Parapeomys, Dendromus) are known from Miocene fossil deposits in eastern Arabia (Thomas et al., 1982; Whybrow and Hill, 1999; Bibi et al., 2013). Nesokia can be discounted based on their more hypsodont teeth with highly developed lophs (see below), whereas extant species of Gerbillinae, Acomys, Apodemus, and Mus can mostly be discounted based on their small size (see Harrison and Bates, 1991). The fossil specimen does, however, fall within the size range of some murid taxa that inhabit Arabia today, such as Rattus and Arvicanthus. However, given that the teeth are heavily worn and do not preserve the loph arrangement, coupled with the poor fossil record for the region, we assign the KAM-4 specimen to the family Muridae.

Genus Nesokia Gray, 1842

Nesokia sp.

Material: KAM-4 NW lake - left maxilla with M1 and M2 in place (KAM-4/002).

Description and remarks: Left maxilla with large, fully hypsodont molars and strongly developed lophs is clearly reminiscent of Nesokia (Fig. 4A); however, it cannot be assigned to species on the basis of the material preserved. M1 and M2 have a combined length of $6 \mathrm{~mm}$. Individual cusps are still visible, suggesting the tooth is in early stages of wear.

Order Proboscidea Illiger, 1811

Family Elephantidae Linnaeus, 1758

Elephantidae sp.

Material: KAM-4 NW lake - various tooth enamel fragments (KAM16/292, unnumbered).

Description and remarks: Tooth enamel fragments were recovered and are consistent with elephantids, but the fragments are small and poorly preserved and little more can be said regarding their taxonomy.

Order Perrisodactyla Owen, 1848

Family Equidae Gray, 1821

Genus Equus Linnaeus, 1758

Equus sp.

Materia: KAM-4 NW lake - intermediate phalanx (KAM16/272).

Description and remarks: An intermediate phalanx (KAM16/272) is that of an equid (Fig. 4D). It is far too large to be one of the wild asses, and its length is consistent with the large African Equus greyvi, some species of extinct Eurasian stenonoid horses (i.e., Equus altidens, Equus suessenbornensis), and wild horse (Equus ferus ferus) (Supplementary Table S1). A principal component analysis (PCA) using five metric variables (Supplementary Table S1) found the KAM-4 specimen to be most similar to E. altidens and E. grevyi (Fig. 5). However, given the poor preservation of the specimen and the fact that the PCA analysis did not discriminate well among taxa on either axis, we refer the KAM-4 specimen to genus only. 


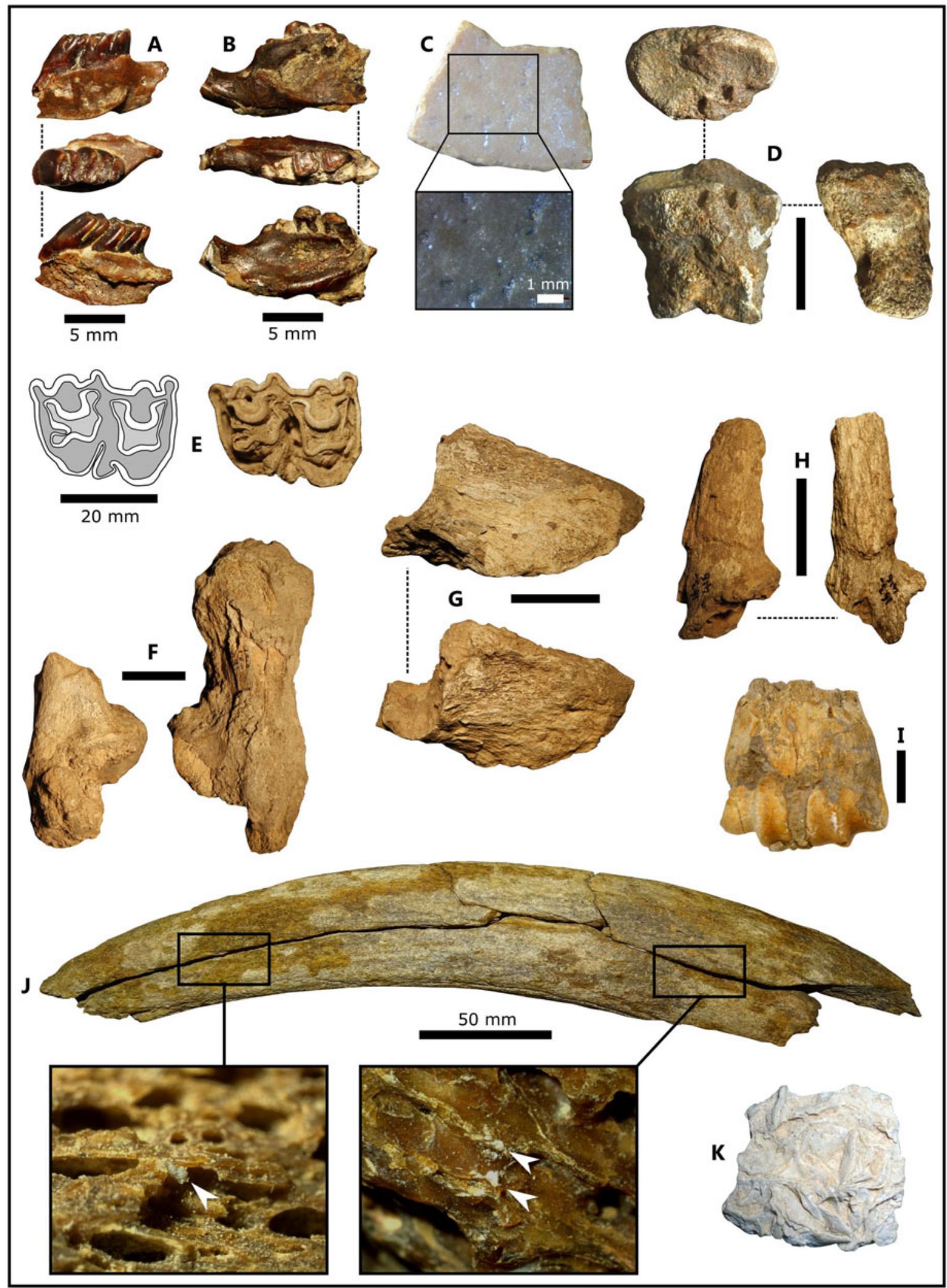

Figure 4. (color online) (A) Left maxilla (KAM-4/002), Nesokia sp.; (B) left mandible (KAM-4/290), Muridae sp.; (C) eggshell fragment (KAM16/547), Struthio sp.; (D) intermediate phalanx (KAM16/272), Equus sp.; (E) M ${ }^{2}$ or $\mathrm{M}^{3}$ (WNEF16_1), cf. Syncerus sp.; (F) complete (16.3/291) and broken (16.3/436) calcanei, Syncerus sp. cf. S. antiquus; (G) right distal phalanx (16.3/unnumbered), Syncerus sp. cf. S. antiquus; (H) right horn core (16.3/416), Antilopinae sp.; (I) distal metapodial (16.3, 16.3/SGS/1060.25), Syncerus sp. cf. S. antiquus; (J) horn core (WNEF16_25) with salt crystals (see insets), Hippotragus sp.; (K) gypsum crystal fossil recovered from the Ti's al Ghadah basin. Scale bars are $30 \mathrm{~mm}$ unless specified. 


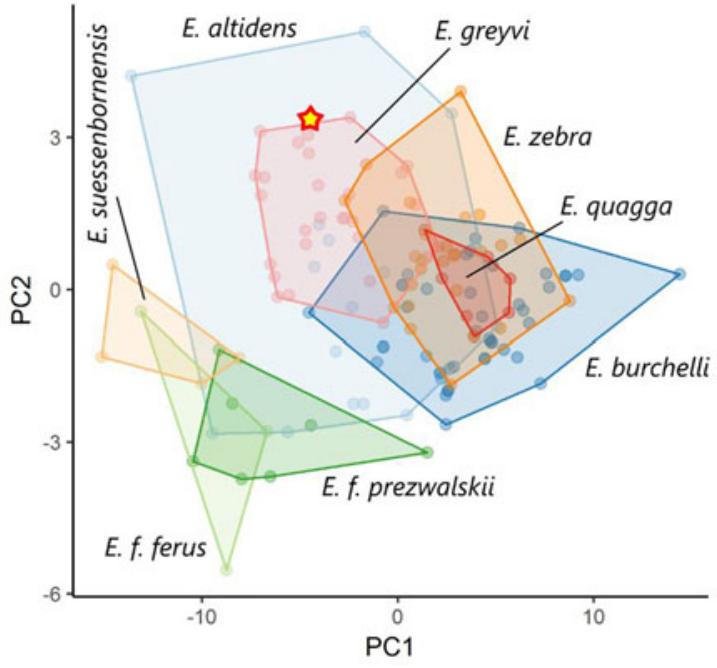

Figure 5. Principal component analysis (PCA) scatter for five metric variables of fossil intermediate phalanx (KAM16/272; yellow and red star) and comparative data from extant and extinct Equus spp. PC1 and PC2 explain $81.4 \%$ and $8.9 \%$ of the variance, respectively. Data from http://www.vera-eisenmann.com (accessed 3 May 2019) and Alberdi and Palombo (2013). (For interpretation of the references to color in this figure legend, the reader is referred to the web version of this article.)

Order Artiodactyla Owen, 1848

Family Hippopotamidae Gray, 1921

Genus Hippopotamus Linnaeus, 1758

Hippopotamus amphibius Linnaeus, 1758.

Referred material: KAM-1 - right third metacarpal (KAM-1/F34); Site 16.3 - two left $(16.3 / 51,210)$ and one right (16.3/437) astragali, four distal metapodials (16.3/33, $84,111,385)$, and proximal, intermediate, and distal phalanges $(16.3 / 82,334 \mathrm{~B}, 334 \mathrm{~A})$.

Description and remarks: A metacarpal recovered from KAM-1 (KAM-1/F34) is referred to a hippopotamid (Fig. 6B). The specimen is bleached white and exhibits cortical exfoliation probably due to wind erosion. The proximal articular surface is triangular in outline and dips to the palmar, while the lateral side extends substantially farther to the proximal than does the medial side, consistent with the third metacarpal of the right forefoot. Its size fits well within the range of modern Hippopotamus amphibius (Supplementary Table S2) and is far too large to be considered Hexaprotodon liberiensis. Thomas et al. (1998) also reported numerous hippopotamid remains from KAM-1. Only a single element was described-a fifth metacarpal (JM 301) "morphologically similar to that of Hippopotamus" but "much more slender" and tentatively referred to Hexaprotodon (Thomas et al., 1998, p. 148). The authors were probably somewhat influenced by their early Pleistocene interpretation of the site and belief that Hexaprotodon occupied the region up until the Holocene (Thomas et al., 1998). Thomas et al. (1998), however, were incorrect. Recent OSL dating found that the KAM-1 lake deposit dated to the late Pleistocene (Rosenberg et al., 2013), while Hip. amphibius is the only known hippopotamid to have occupied Africa and southwest Asia during this time (Stewart et al., 2019b). The material described here, and probably the material reported by Thomas et al. (1998), can be referred to Hip. amphibius.

Hippopotamid remains are relatively abundant at Site 16.3 $(n=23)$ and consist primarily of fragmented appendicular and axial remains. A well-preserved and complete right astragalus (16.3/51) is too large and squamate to be that of a Hexaprotodon sp. and is consistent in overall shape and size to Hip. amphibius (Fig. 6A, Supplementary Table S3). Two additional astragali $(16.3 / 210,437)$, preserving only the distal end, are of similar size and morphology (Fig. 6A). Three distal metapodial fragments $(16.3 / 84,111$, 385 ), representing the third or fourth metapodials, resemble those of Hip. amphibius in their large width and horizontally positioned distal epiphyses (Fig. 6D, Supplementary Table S4), which contrast to the more obliquely placed distal epiphyses of Hex. liberiensis (Hooijer, 1950). A smaller and more obliquely positioned distal metapodial (16.3/33) may represent a second or fifth metapodial and, if correct, is too large to be considered Hex. liberiensis (Supplementary Table S4). Two robust proximal phalanges $(16.3 / 35,82)$ can be attributed to either the second or third digits, one of which can be referred to as a juvenile on the basis of its unfused (and absent) proximal epiphysis (Fig. 6C). A distal phalanx (16.3/334A) with a greatest breadth measuring $27 \mathrm{~mm}$ and a poorly preserved intermediate phalanx (16.3/ 334B) are also referred to Hippopotamus. Given the late Pleistocene age of the lake with which the fossil remains are associated (Rosenberg et al., 2013) and similarities between the hippopotamid fossils and Hip. amphibius, we attribute the Site 16.3 remains to the extant Hip. amphibius accordingly.

\section{Hippopotamus sp.}

Material: KAM-4 NW lake - right astragalus (KAM-4/ 010).

Description and remarks: A right astragalus (KAM4/010) recovered from KAM-4 NW lake is similar in overall size and morphology to Hip. amphibius (Fig. 6E). The specimen is, however, poorly preserved and distorted, making a specific assignment difficult, and we refer this specimen to Hippopotaтиs sp. accordingly.

\section{cf. Hippopotamus sp.}

Material: KAM-4 NE lake - femur head (KAM-4/7015), distal fibula (KAM-4/7016).

Description and remarks: Two specimens recovered from KAM-4 NE lake are probably a hippopotamid but are too incomplete to be confidently attributed - a large globular femur head (Fig. 6F) with a diameter of $77.6 \mathrm{~mm}$ and a distal fibula. 


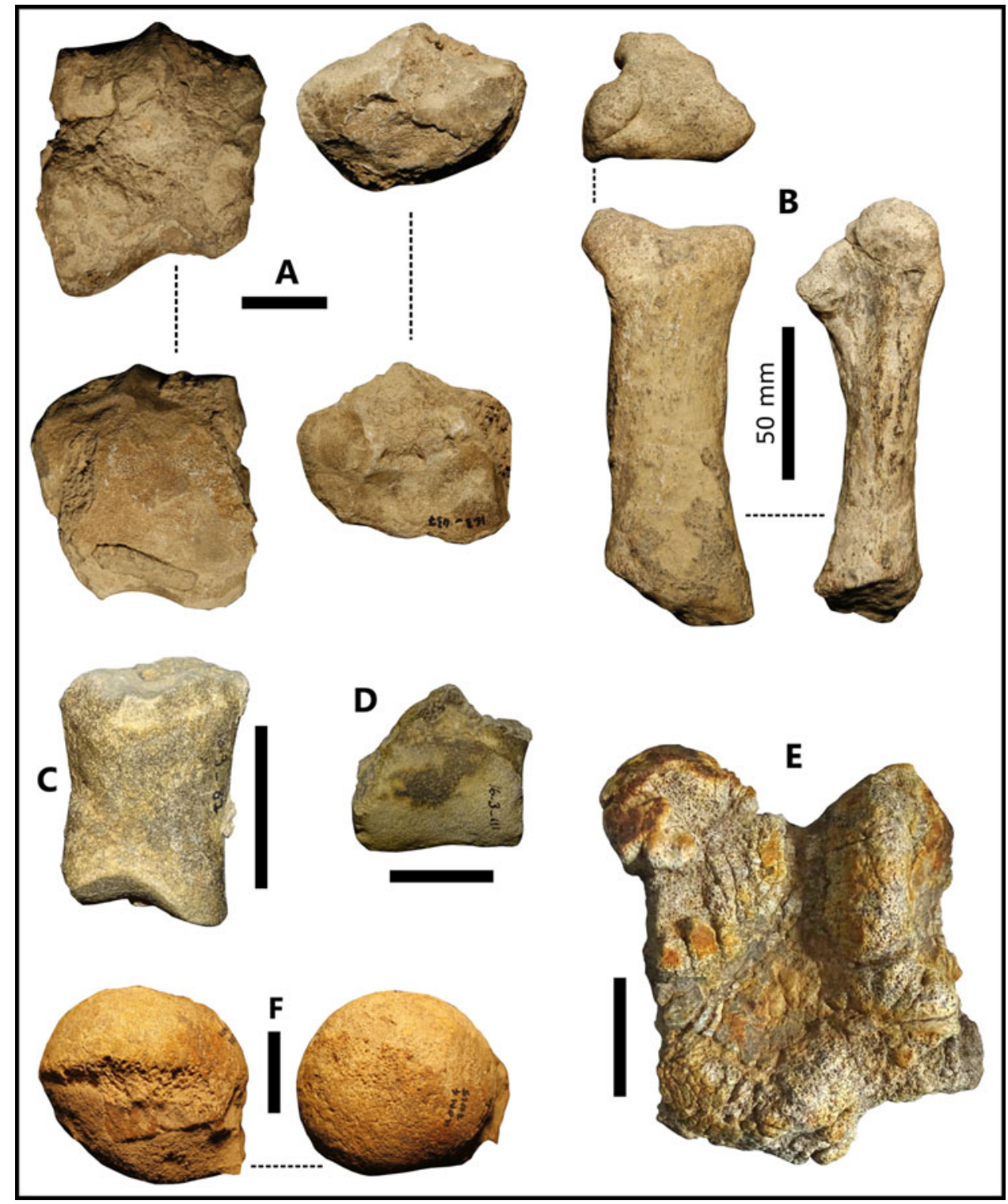

Figure 6. (color online) Hippopotamid remains. (A) Right (16.3/51) and left (16.3/437) astragali, Hippopotamus amphibius; (B) right third metacarpal (KAM-1/F38), Hip. amphibius; (C) juvenile proximal phalanx of the second or third digit (16.3/82), Hip. amphibius; (D) distal metapodial fragment (16.3/111), Hip. amphibius; (E) astragalus (KAM-4/010), Hippopotamus sp.; (F) femur head (KAM-4 NE lake, KAM-4/ 7015), cf. Hippopotamus. Scale bars are $30 \mathrm{~mm}$ unless specified.

Family Bovidae Gray, 1821

Genus Syncerus Hodgson, 1847

Syncerus sp. cf. S. antiquus Duvernoy, 1851.

Referred material: Site 16.3 - right distal phalanx (unnumbered), a right and left calcaneum (16.3/291 and 16.3/436), distal metapodial (16.3/SGS/1060.19), and proximal tibia (16.3/SGS/1060.25); KAM-1 - left distal humerus (KAM-1/F38).

Description and remarks: Numerous fossils represent a large buffalo, and while most of the specimens are fragmented, some are complete enough to provide taxonomic insight. A distal phalanx (16.3/unnumbered; Fig. 4G) with a curved plantar surface and poorly developed processes extensorius and tuberculum flexorium is consistent with Syncerus and Pelorovis, but not Bos (Peters, 1986; Thomas et al., 1998). Its length falls outside the size range reported for the extant Syncerus caffer (Supplementary Table S5), and in this respect it more closely resembles the larger extinct Syncerus antiquus (placed within Syncerus rather than Pelorovis following Gentry [2010]) and Pelorovis. Indeed, its size closely matches the Pelorovis sp. cf. P. oldowayensis distal phalanx reported from KAM-1 (Thomas et al., 1998; but see below). Two calcanea $(16.3 / 291,436)$ are consistent with those of Bos and $S$. antiquus in size and in exhibiting a short sustentaculum tali and well-developed processes coracoideus, features that are absent in S. caffer (Gentry, 1967; Peters, 
1986; Fig. 4F, Supplementary Table S5). A distal metapodial (16.3/SGS/1060.19) is larger than those of $S$. caffer and Bos but comparable to late Pleistocene $S$. antiquus remains from Africa, while a proximal tibia (16.3/SGS/ 1060.25) also exceeds the size ranges reported for the S. caffer and Bos (Supplementary Table S5). We therefore refer the Site 16.3 large bovid material to Syncerus and note that the late Pleistocene age of the site makes attribution to $S$. antiquus most likely.

A large bovid distal humerus (KAM-1/F38) recovered from KAM-1 is provisionally referred to $S$. antiquus, as its size exceeds those of $S$. caffer and Bos (Supplementary Table S5). Thomas et al. (1998) also reported remains of a large buffalo from KAM-1, which were provisionally attributed to $P$. oldowayensis. However, as discussed elsewhere (Stewart et al., 2019b), more recent dating of the KAM-1 palaeolake to the late Pleistocene is suggestive of the younger species $S$. antiquus. The specimen described here, and probably those reported by Thomas et al. (1998), can be provisionally referred to the late Pleistocene S. antiquus.

\section{cf. Syncerus sp.}

Referred material: WNEF16_1 - a single complete M2 or M3 (WNEF16_1).

Description and remarks: A single complete M2 or M3 (WNEF16_1; Fig. 4E) differs from Bubalus in its less complex occlusal outline, while the infundibulum of the distal loop exhibits a marked internal fold as seen in Syncerus and Pelorovis, and sometimes in Bos, albeit typically less pronounced (Martínez-Navarro et al., 2007). The small and simple basal pillar is consistent with Pelorovis and S. antiquus, whereas those of other large Bovinae are typically more complex and medially pronounced (Gentry, 1967). That said, rare examples of $S$. caffer with relatively short basal pillars were encountered when examining comparative material. Its size (occlusal length $=31.6 \mathrm{~mm}$, posterior lobe width $=21.3$ ) is comparable to $S$. caffer and $S$. antiquus. The former is unknown from north of the Sahara, while the latter populated southwest Asia during the Pleistocene (Stewart et al., 2019b). Therefore, we provisionally attribute the WNEF16_1 specimen to Syncerus.

Subfamily Antilopinae Gray, 1921

Antilopinae sp.

Material: Site 16.3 - right horn core (16.3/416).

Description and remarks: A small right horn corn (Fig. 4H) with backward curvature, slight torsion, some mediolateral compression, and flattened lateral side is referred to gazelle (Gentry and Gentry, 1978). The transverse and anteroposterior diameters measured $21.9 \mathrm{~mm}$ and $28.1 \mathrm{~mm}$, respectively. The size and compression index $(77.9 \mathrm{~mm})$ are consistent with various species of gazelle, including Gazella dorcas and Nanger soemmeringii (Gentry, 1964; Gentry and Gentry, 1978).
Subfamily Hippotraginae Brooke, 1876

Genus Hippotragus Harris, 1838

Hippotragus sp.

Material: WNEF16_25 - horn core (WNEF16_25).

Description: A single fragmented but well-preserved and near-complete horn core (Fig. 4J). The horn core exhibits strong mediolateral compression and is without torsion, keels, or ridges, matching those of the living Hippotragus spp. The preserved length along the anterior of the horn core is $370 \mathrm{~mm}$, but its original length may have been substantially longer. Given the fragmentary nature of the specimen and lack of morphometric data, only a generic assignment is possible.

Genus Oryx de Blainville, 1816

Oryx sp.

Referred material: Site 16.3 - horn core (16.3/415); KAM-4 Lake S lake - two horn cores (KAM-4/7059, 7088); KAM-4 NW lake - occipital bone with two partially preserved horn cores (KAM-4/014); WNEF16_20 - horn core (WNEF16_20).

Description and remarks: Small, straight semicircular horn cores without torsion attributable to the genus Oryx were recovered from numerous sites. The basal horn core dimensions of the KAM-4 NW lake specimen (KAM-4/014) are larger than comparative material of the Arabian endemic Oryx leucoryx, smaller than Oryx gazella and Oryx beisa, and within the range of the desert-adapted Oryx dammah (Supplementary Table S6). The KAM-4 NW lake specimen differs from the latter in having more widely diverging horn cores, but in this regard is comparable to all other living species. It differs from the fossil specimens from the nearby middle Pleistocene site of Ti's al Ghadah in being less robust and having more divergent horn cores (Thomas et al., 1998; Stimpson et al., 2016). Stimpson et al. (2016) suggested that the large and robust Oryx fossils from Ti's al Ghadah might represent a now-extinct large-bodied Pleistocene form of O. leucoryx. Given the intermediate size of the specimens described here, it is possible that the KAM-4 NW lake specimen represents a transitional form between the large-bodied middle Pleistocene Oryx and the smaller, extant Arabian O. leucoryx.

\section{Taphonomic analysis}

Various taphonomic considerations and their role in shaping the Arabian Pleistocene fossil assemblages are discussed in the following sections. The sites with limited fossil material (i.e., WNEF16_20, WNEF16_22, and WNEF16_25) are excluded from the discussions unless otherwise specified. Full results of the quantitative and qualitative taxonomic and taphonomic analysis are presented in Tables 1-3 (raw data in Supplementary Tables S7 and S8) and complete skeletal inventory in Supplementary Table S9. 
Table 1. Taxonomic list. ${ }^{\text {a }}$

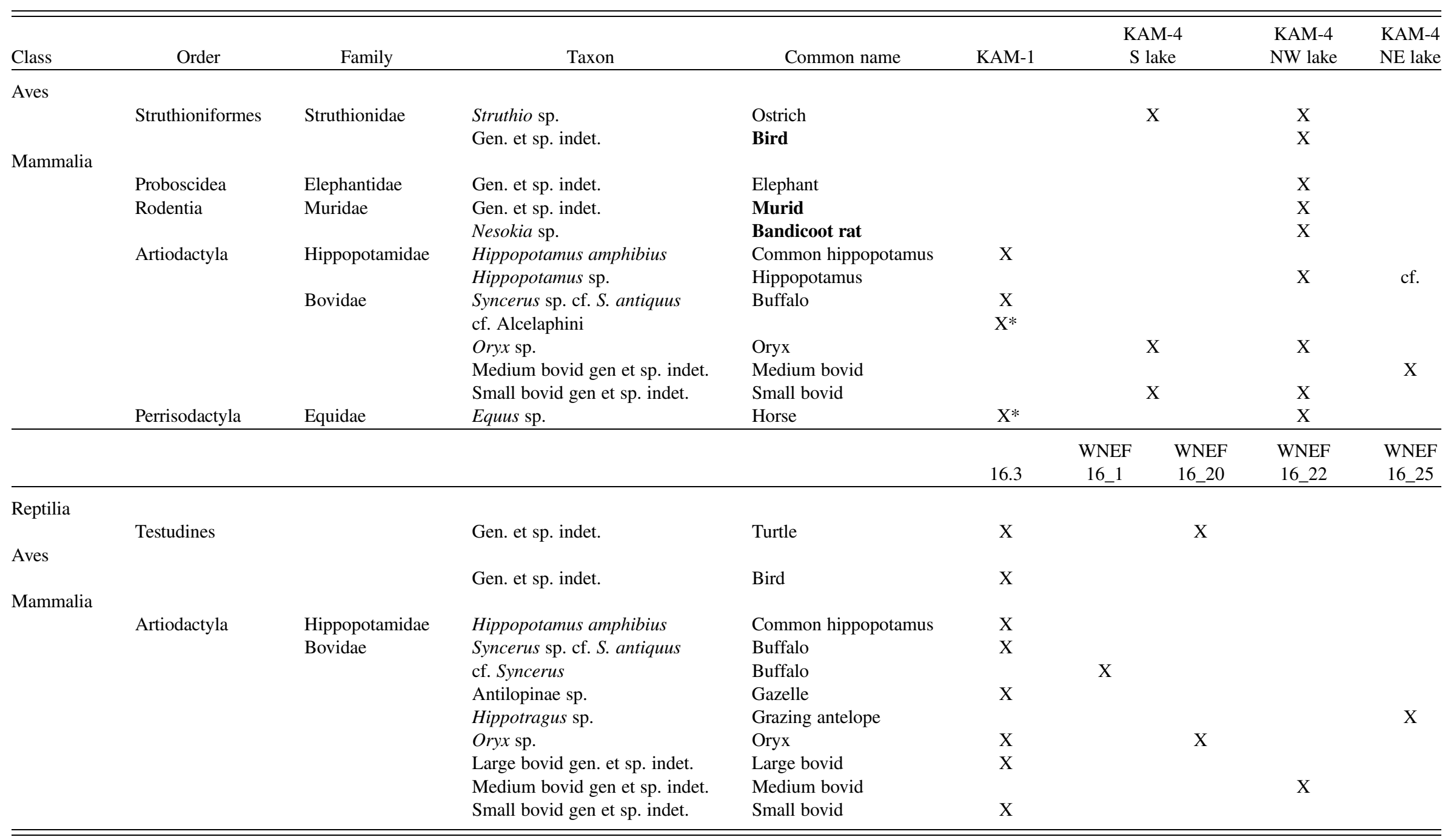

${ }^{a}$ Asterisks $(*)$ indicate taxa listed in Thomas et al. (1998). Taxa listed in bold recovered during excavation. 
Table 2. Taxonomic representation according to number of identified specimens (NISP) and minimum number of individuals (MNI).

\begin{tabular}{|c|c|c|c|c|c|c|c|c|c|}
\hline & KAM-1 & $\begin{array}{l}\text { KAM-4 } \\
\text { S lake }\end{array}$ & $\begin{array}{c}\text { KAM-4 } \\
\text { NW lake }\end{array}$ & $\begin{array}{c}\text { KAM-4 } \\
\text { NW lake } \\
\text { excavated }\end{array}$ & $\begin{array}{l}\text { KAM-4 } \\
\text { NE lake }\end{array}$ & 16.3 & $\begin{array}{c}\text { WNEF } \\
16 \_1 \\
\end{array}$ & $\begin{array}{l}\text { WNEF } \\
16 \_20 \\
\end{array}$ & $\begin{array}{l}\text { WNEF } \\
16 \_22 \\
\end{array}$ \\
\hline NRSP & 76 & 67 & 596 & 22 & 17 & 615 & 213 & 7 & 4 \\
\hline Small-size animal & 1 & 5 & 38 & 15 & 0 & 9 & 0 & 3 & 1 \\
\hline Medium-sized animal & 45 & 52 & 545 & 7 & 12 & 302 & 0 & 4 & 2 \\
\hline Large-sized animal & 30 & 0 & 12 & 0 & 5 & 201 & 213 & 0 & 1 \\
\hline NISP & 34 & 37 & 229 & 17 & 9 & 150 & 102 & 3 & 3 \\
\hline \multicolumn{10}{|l|}{ NISP by taxon } \\
\hline Aves & 0 & 1 & 10 & 10 & 0 & 1 & 0 & 0 & 0 \\
\hline Testudines & 0 & 0 & 3 & 0 & 0 & 3 & 0 & 3 & 0 \\
\hline Rodentia & 0 & 0 & 5 & 3 & 0 & 0 & 0 & 0 & 0 \\
\hline Elephantidae & 0 & 0 & 1 & 0 & 0 & 0 & 0 & 0 & 0 \\
\hline Hippopotamidae & 2 & 0 & 1 & 0 & 2 & 23 & 0 & 0 & 0 \\
\hline Small-sized Bovidae & 0 & 3 & 8 & 1 & 0 & 2 & 0 & 0 & 0 \\
\hline Medium-sized Bovidae & 1 & 22 & 32 & 2 & 1 & 3 & 213 & 2 & 1 \\
\hline Large-sized Bovidae & 2 & 0 & 0 & 0 & 0 & 110 & 0 & 0 & 0 \\
\hline$\underline{\text { Equidae }}$ & 0 & 0 & 1 & 0 & 0 & 2 & 0 & 0 & 0 \\
\hline \multicolumn{10}{|l|}{ MNI by taxon } \\
\hline Aves & 0 & 0 & 1 & 1 & 0 & 1 & 0 & 0 & 0 \\
\hline Testudines & 0 & 0 & 0 & 0 & 0 & 1 & 0 & 1 & 0 \\
\hline Rodentia & 0 & 0 & 2 & 2 & 0 & 0 & 0 & 0 & 0 \\
\hline Elephantidae & 0 & 0 & 1 & 0 & 0 & 0 & 0 & 0 & 0 \\
\hline Hippopotamidae & 1 & 0 & 1 & 0 & $1(?)$ & 2 & 0 & 0 & 0 \\
\hline Small-sized Bovidae & 0 & 1 & 1 & 1 & 0 & 1 & 0 & 0 & 0 \\
\hline Medium-sized Bovidae & 1 & 2 & 3 & 1 & 1 & 1 & 0 & 1 & 1 \\
\hline Large-sized Bovidae & 1 & 0 & 0 & 0 & 0 & 1 & 1 & 0 & 0 \\
\hline Equidae & $1 *$ & 0 & 1 & 0 & 0 & 1 & 0 & 0 & 0 \\
\hline
\end{tabular}

\section{Khall Amayshan-1 (KAM-1)}

Fossils were recovered from within and atop the uppermost marl unit at KAM-1 (see Rosenberg et al. [2013] and Scerri et al. [2015] for detailed descriptions of the entire sequence). It should be noted that Thomas et al. (1998) also collected fossils at this site that are not included in this analysis, and, therefore, the fossils studied here may not be an accurate reflection of the original taphocoenosis. To the best of our knowledge, no other fossils have been collected from the other sites analysed here.

Seventy-six fossils were recovered at KAM-1, representing four taxa and matching those reported by Thomas et al. (1998). Small vertebrate remains are absent, and small fossils in general are underrepresented at the site (Fig. 7). Fossils range in colour from light brown and grey to bleached white (Fig. 8E), and several specimens exhibit manganese staining. No fossils were unweathered, and most exhibited stage 2 and 3 weathering $(n=31,81 \%)$. For two-thirds of the fossils it was impossible to determine weathering stage due to significant abrasion and cortical exfoliation, and this is the case for most assemblages analysed here. Wind abrasion appears to have been particularly pronounced in the KAM-1 fossil assemblage, and all specimens exhibit some degree of rounding, pitting, and polish, with some fossils having been reduced to near pebbles (Fig. 8F).

Limb-bone elements dominate the assemblage $(n=25$, $76 \%$ of NISP) and long-bone midshafts make up most of these ( $n=15,45 \%$ of NISP). Most midshafts have fracture angle, outline, and edge characteristics consistent with dry fracturing $(n=14,74 \%)$, and most retain their complete circumference $(n=12,67 \%)$. A handful of specimens exhibit plastic deformation (i.e., crushing), suggesting that the site once lay under a significant weight of sediment, and rare instances of plastic deformation were also observed in the KAM-4 and Site 16.3 assemblages (e.g., Fig. 8I). Easily transported elements (Voorhies groups I and II) are best represented, and the tooth to vertebrae ratio $(T / V=2.5)$ falls between the values reported by Behrensmeyer and Dechant Boaz (1980) for minimal and strong hydraulic sorting.

\section{Khall Amayshan-4 (KAM-4) NW lake}

Renewed investigations at KAM-4 revealed previously unrecognised palaeolake deposits (Fig. 2), and fossils were recovered from the surfaces of three of these: KAM-4 NW lake, KAM-4 NE lake, and KAM-4 S lake. The KAM-4 NW 
Table 3. Results of the taphonomic analysis (\% number of recovered specimens data).

\begin{tabular}{|c|c|c|c|c|c|c|c|c|c|c|}
\hline & & KAM-1 & $\begin{array}{c}\text { KAM-4 } \\
\text { S lake }\end{array}$ & $\begin{array}{l}\text { KAM-4 } \\
\text { NW lake }\end{array}$ & $\begin{array}{c}\text { KAM-4 } \\
\text { NW lake } \\
\text { excavated }\end{array}$ & $\begin{array}{l}\text { KAM-4 } \\
\text { NE lake }\end{array}$ & 16.3 & $\begin{array}{c}\text { WNEF } \\
16 \_1 \\
\end{array}$ & $\begin{array}{l}\text { WNEF } \\
16 \_20\end{array}$ & $\begin{array}{l}\text { WNEF } \\
16 \_22 \\
\end{array}$ \\
\hline \multicolumn{11}{|l|}{ Weathering } \\
\hline 0 & $\%$ & 0 & 10 & 7.3 & 58.8 & 0 & 10.3 & 1.7 & 0 & 0 \\
\hline 1 & $\%$ & 11.5 & 16 & 9.2 & 11.8 & 0 & 17.7 & 6.4 & 0 & 0 \\
\hline 2 & $\%$ & 7.7 & 54 & 24.3 & 5.9 & 33.3 & 28 & 37 & 33.3 & 0 \\
\hline 3 & $\%$ & 46.2 & 20 & 50 & 11.8 & 50 & 35.8 & 47.4 & 66.6 & 50 \\
\hline 4 & $\%$ & 34.6 & 0 & 9.2 & 11.8 & 16.7 & 8.1 & 6.9 & 0 & 50 \\
\hline 5 & $\%$ & 0 & 0 & 0 & 0 & 0 & 0 & 0.6 & 0 & 0 \\
\hline Tooth-marked & $\%$ & 1.3 & 14.9 & 1.3 & 0 & 29.4 & 6.3 & 0 & 0 & 0 \\
\hline \multicolumn{11}{|l|}{ Circ. comp. ${ }^{\mathrm{a}}$} \\
\hline Type 1 & $\%$ & 22.2 & 80 & 77.8 & 0 & 57.1 & 65.4 & 100 & - & - \\
\hline Type 2 & $\%$ & 11.1 & 0 & 2.8 & 0 & 0 & 7.7 & 0 & - & - \\
\hline Type 3 & $\%$ & 66.7 & 20 & 19.4 & 100 & 42.9 & 26.9 & 0 & & - \\
\hline \multicolumn{11}{|l|}{ Breakage } \\
\hline Dry & $\%$ & 70 & 75 & 72 & 100 & 50 & 61.5 & 18.5 & - & - \\
\hline Green & $\%$ & 20 & 25 & 22 & 0 & 50 & 30.8 & 64.6 & - & - \\
\hline Both & $\%$ & 10 & 0 & 6 & 0 & 0 & 7.7 & 16.9 & 一 & 一 \\
\hline \multicolumn{11}{|l|}{ Voorhies group } \\
\hline I & $\%$ & 30.8 & 21.7 & 50.8 & - & - & 44.3 & - & - & - \\
\hline I and II & $\%$ & 15.4 & 47.8 & 13.3 & - & - & 16.5 & - & - & - \\
\hline II & $\%$ & 53.8 & 26.1 & 29.7 & - & - & 30.4 & - & - & - \\
\hline II and III & $\%$ & 0 & 0 & 3.1 & - & - & 0 & - & - & - \\
\hline III & $\%$ & 0 & 4.3 & 0.8 & - & - & 8.7 & - & - & - \\
\hline Tooth/vertebrae & $\mathrm{n} / \mathrm{n}$ & 2.5 & 0.2 & 0.03 & - & - & 0 & - & - & - \\
\hline Manganese staining & & $\mathrm{Y}$ & $\mathrm{Y}$ & $\mathrm{Y}$ & $\mathrm{Y}$ & $\mathrm{Y}$ & $\mathrm{Y}$ & $\mathrm{N}$ & $\mathrm{Y}$ & $\mathrm{N}$ \\
\hline Root etching & & $\mathrm{N}$ & $\mathrm{Y}$ & $\mathrm{Y}$ & $\mathrm{N}$ & $\mathrm{N}$ & $\mathrm{Y}$ & $\mathrm{Y}$ & $\mathrm{N}$ & $\mathrm{N}$ \\
\hline
\end{tabular}

${ }^{\mathrm{a} C i r c . ~ c o m p ., ~ l o n g-b o n e ~ c i r c u m f e r e n c e ~ c o m p l e t e n e s s . ~}$

lake fossils were found concentrated on a sandy area between two of the excavated trenches (Trenches 1 and 3 ) that is interpreted as an ancient sandspit that led into the lake. Twenty-two fossils were discovered during excavations and represent the first time that fossils have been recovered from within stratigraphy at the site.

The KAM-4 NW lake assemblage is one of the largest and most taxonomically diverse sites reported here, with a total of 596 fossils representing eight taxa. Remains of small vertebrates-which comprise rodents, birds, tortoises, and small bovids-were recovered from atop the deposit and during the excavation of palaeolake sediments and were relatively more abundant in the latter. Medium-sized animals dominate the assemblage, and it seems likely that most of this material is attributable to one or several medium-sized bovids (e.g., Oryx). Large-sized animals are very rare, but recovered materials indicate the presence of Hippopotamus and an elephantid.

Fossils range in colour from grey and light brown to maroon, the latter being more characteristic of the excavated assemblage (Fig. 4A and B). Manganese staining and root etching were occasionally observed, and two bone fragments recovered during excavation are blackened and appear burnt, although additional analyses are needed to confirm this. Likewise, the KAM-4 NW lake assemblage appears significantly impacted by wind abrasion, with all fossils exhibiting rounding, pitting, and polish, and in some instances significant exposure of cancellous bone (e.g., Fig. 8C). Interspecimen differences in abrasion, more characteristic of wind abrasion, were also observed (e.g., Fig. 8D). The fossils for which weathering could be reliably determined range between weathering stages 0 and 4 , with most falling into the latter two stages $(\mathrm{n}=153,74 \%)$, and a Spearman's test found a significant positive correlation between specimen size (length) and weathering stage (Spearman's rho, $\left.r_{\mathrm{s}}=0.166, P<0.018\right)$. A small number of fossils, mostly appendicular elements, show evidence of carnivore gnawing $(\mathrm{n}=8,1.3 \%)$.

Limb-bone elements make up nearly half of the identifiable material $(n=109,47 \%$ of NISP) followed by vertebrae $(n=$ $58,25 \%$ of NISP) and small compact bones like phalanges, carpals, and tarsals $(n=33,14 \%$ of NISP). Most limb bones are fragmented such that they retain less than half of their circumference $(n=56,78 \%)$ and exhibit features typical of dry fracturing $(n=36,72 \%)$. Abundant fragile vertebrae and small animal remains (e.g., birds, rodents) suggest that 


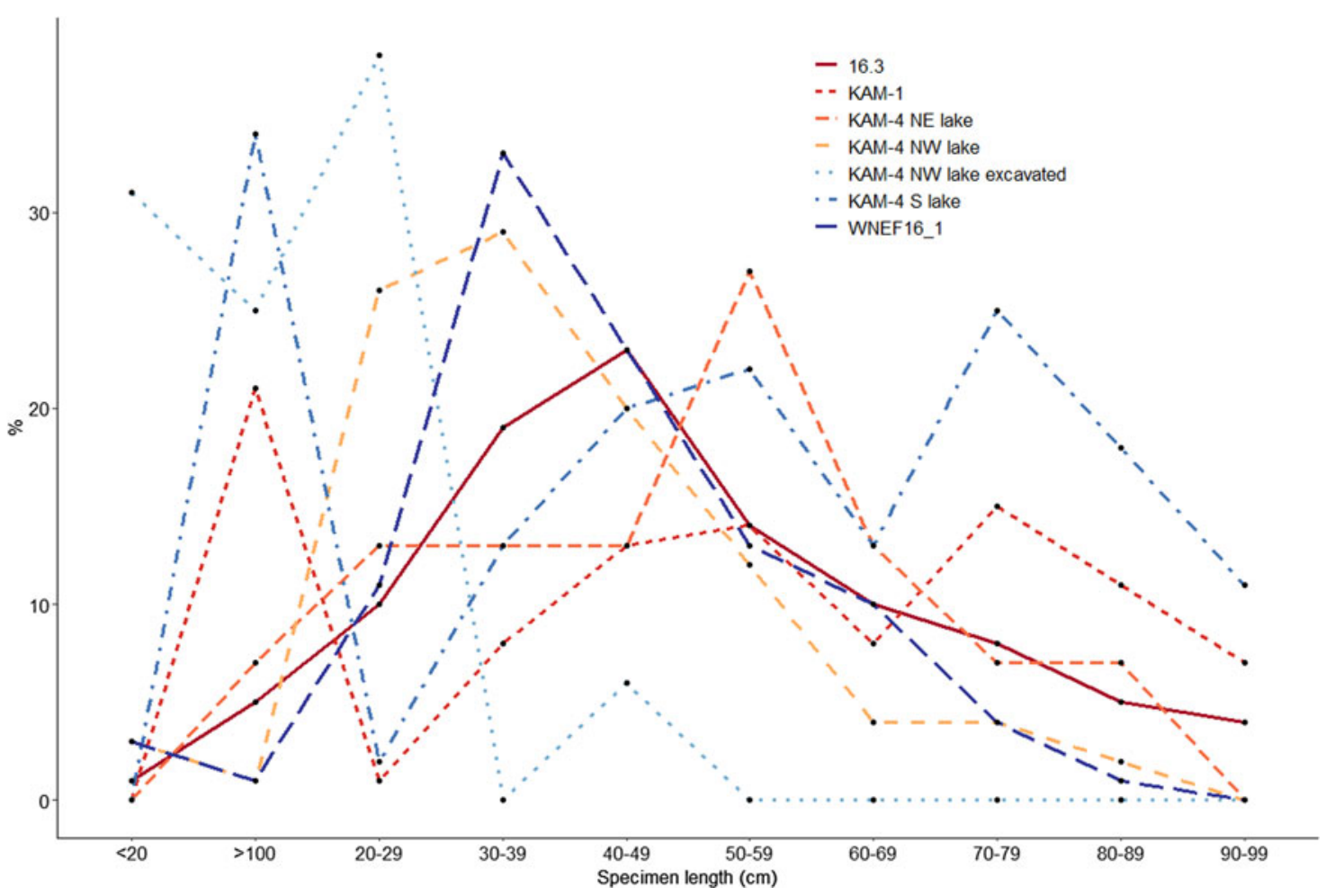

Figure 7. (color online) Distribution of frequencies (\%) for each specimen size range.

the assemblage has undergone minimal density-mediated attrition. This is also borne out by the lack of correlation between medium-sized bovid long-bone survivorship (MNE) and wildebeest bone mineral density (Spearman's rho, $r_{\mathrm{s}}=-0.192, P=0.369$; Supplementary Table S11). This should, however, be interpreted with caution, given the heavily fragmented nature of the limb-bone portion of this assemblage (see Marean et al., 2004; Clark, 2019). There is a clear bias toward easily transported elements (Voorhies groups I and II) and hydraulic winnowing is also supported by the low tooth to vertebrae ratio $(T / V=0.03)$. Very small animal remains (rodents, birds, and tortoise)which are relatively abundant at the site-also support the preferential transport of easy-to-transport remains. However, the bulk of these findings $(n=13,72.2 \%)$ were recovered from the excavated portion of the assemblage, suggesting that once exposed, microfaunal remains are transported or destroyed. Alternatively, microfaunal remains may have been simply missed during pedestrian surveys, and more intensive surveys should be undertaken in the future to test for this.

\section{Khall Amayshan-4 (KAM-4) NE lake}

The NE lake fossil assemblage is the smallest and least diverse of the KAM-4 fossil deposits, with only 17 fossils representing two taxa. Small vertebrates are absent, mediumsized animals make up about two-thirds of the assemblage, while large animals make up the remaining third and indicate the possible presence of Hippopotamus.
Fossils are typically brown in colour and some are manganese stained. Fossils show weathering stages $2-4$ with stage 3 being most common $(n=6,50 \%)$. All fossils exhibit rounding, pitting, and/or polish consistent with abrasion by windblown sediment. All identified specimens are appendicular elements, half of which are long-bone midshaft fragments $(\mathrm{n}=5,56 \%$ of NISP). Carnivore tooth-marked specimens are relatively common $(\mathrm{n}=5,29 \%)$ and include two measurable tooth pits with dimensions of $2.8 \times 2.2 \mathrm{~mm}$ and $4.6 \times$ $3.6 \mathrm{~mm}$ (Supplementary Table S10). Green- $(\mathrm{n}=2,50 \%)$ and dry-fractured $(\mathrm{n}=2,50 \%)$ long bones are equally abundant, and long bones retaining less than half $(n=4,57 \%)$ and their complete circumference $(n=3,43 \%)$ are similarly represented.

\section{Khall Amayshan-4 (KAM-4) S lake}

Sixty-seven fossils were recovered from the KAM-4 S lake representing at least two taxa. Small vertebrates are represented by a few small bovid remains as well as a single piece of ostrich eggshell, which, given that ostriches inhabited the Arabian Peninsula until historic times (Potts, 2001), may be of more recent origin. Medium-sized mammals make up the remainder of the fossil material, and it appears that much of this material is attributable to one or several medium-sized bovids (e.g., Oryx).

Fossils range from dark brown to maroon, exhibit rounding and pitting characteristic of wind abrasion, and occasional root etching and manganese staining (e.g., Fig. 8G). Fossils appear less weathered than at the other 


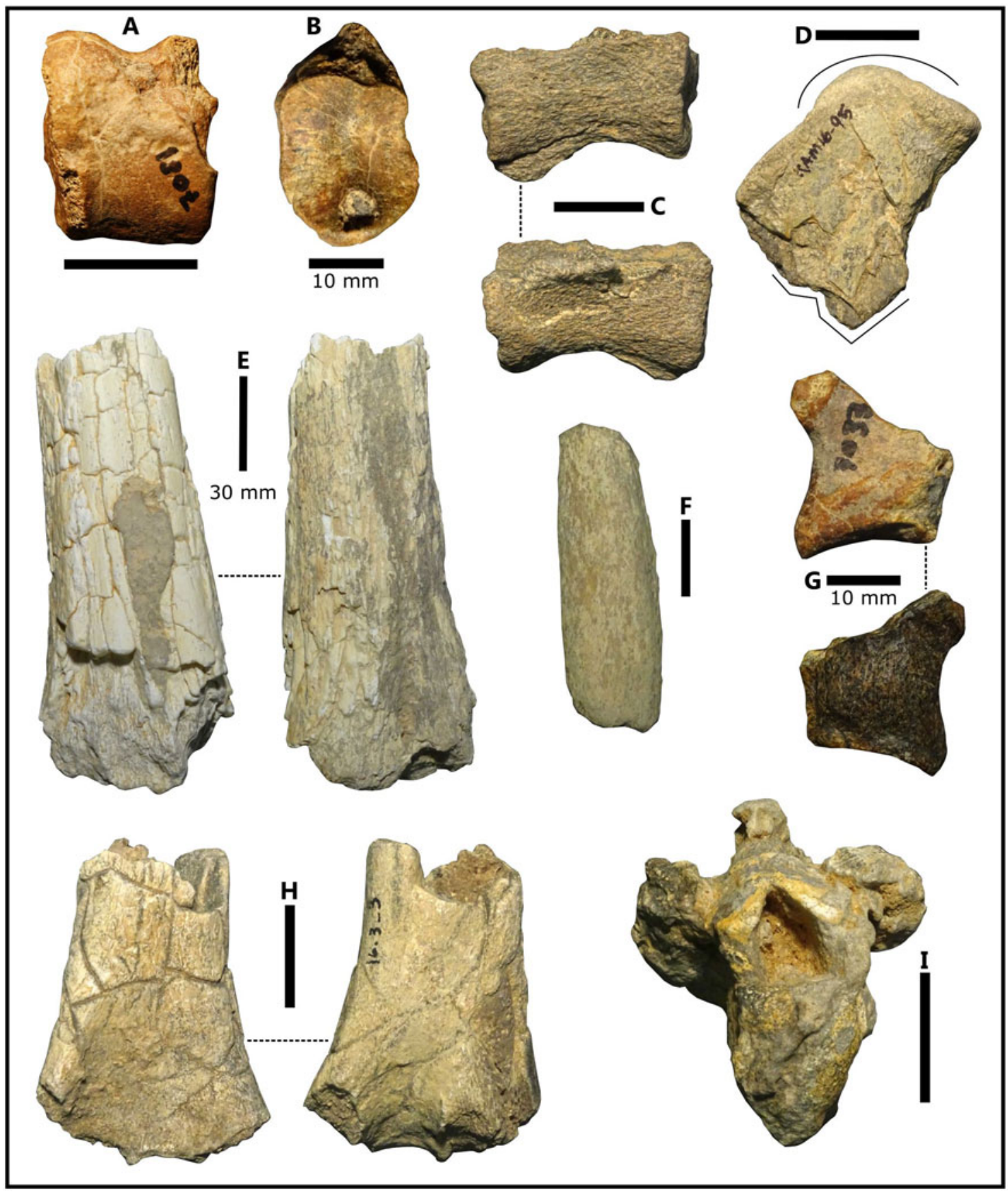

Figure 8. (color online) Examples of taphonomic modifications. (A) Carnivore-gnawed bovid astragalus (KAM 4 S lake; KAM-4/7081); (B) bovid distal phalanx with carnivore tooth puncture (KAM 4 S lake; KAM-4/7033); (C) wind-eroded vertebra centrum with cancellous bone exposed (KAM 4 NW lake); (D) unidentified fragment displaying rounding and slight polish on one side (top) and sharp edges on the other (bottom) (KAM 4 NW lake; KAM-16/95); (E) large midshaft heavily wind-abraded and bleached on one side (left) and less bleached and displaying weathering stage 4 on the other (right) (KAM1); (F) heavily wind-abraded midshaft fragment of large animal (KAM1); (G) manganese-stained fragment (KAM 4 S lake; KAM4/7033); (H) bovid distal humerus exhibiting post-fossilisation root damage (16.3_3); (I) plastically deformed thoracic vertebrae (KAM 4 NW lake; KAM16/71). Scale bars are 20 mm unless otherwise specified.

sites investigated here, reaching maximally to weathering stage 3 and with most falling into stage $2(n=27,54 \%)$. Carnivore tooth-marked bones are relatively abundant $(\mathrm{n}=10,15 \%)$ and a single tooth pit measured $5.0 \times$ $4.4 \mathrm{~mm}$ (Supplementary Table S10). Most midshaft fragments are represented by pieces retaining less than half their circumference $(n=4,80 \%)$, and most of these have fracture angle, shape, and edge characteristics consistent with dry fracturing $(n=6,75 \%)$.

\section{Site 16.3}

Follow-up investigations at Site 16.3 showed additional sandy marl sediments situated above the upper diatomite 


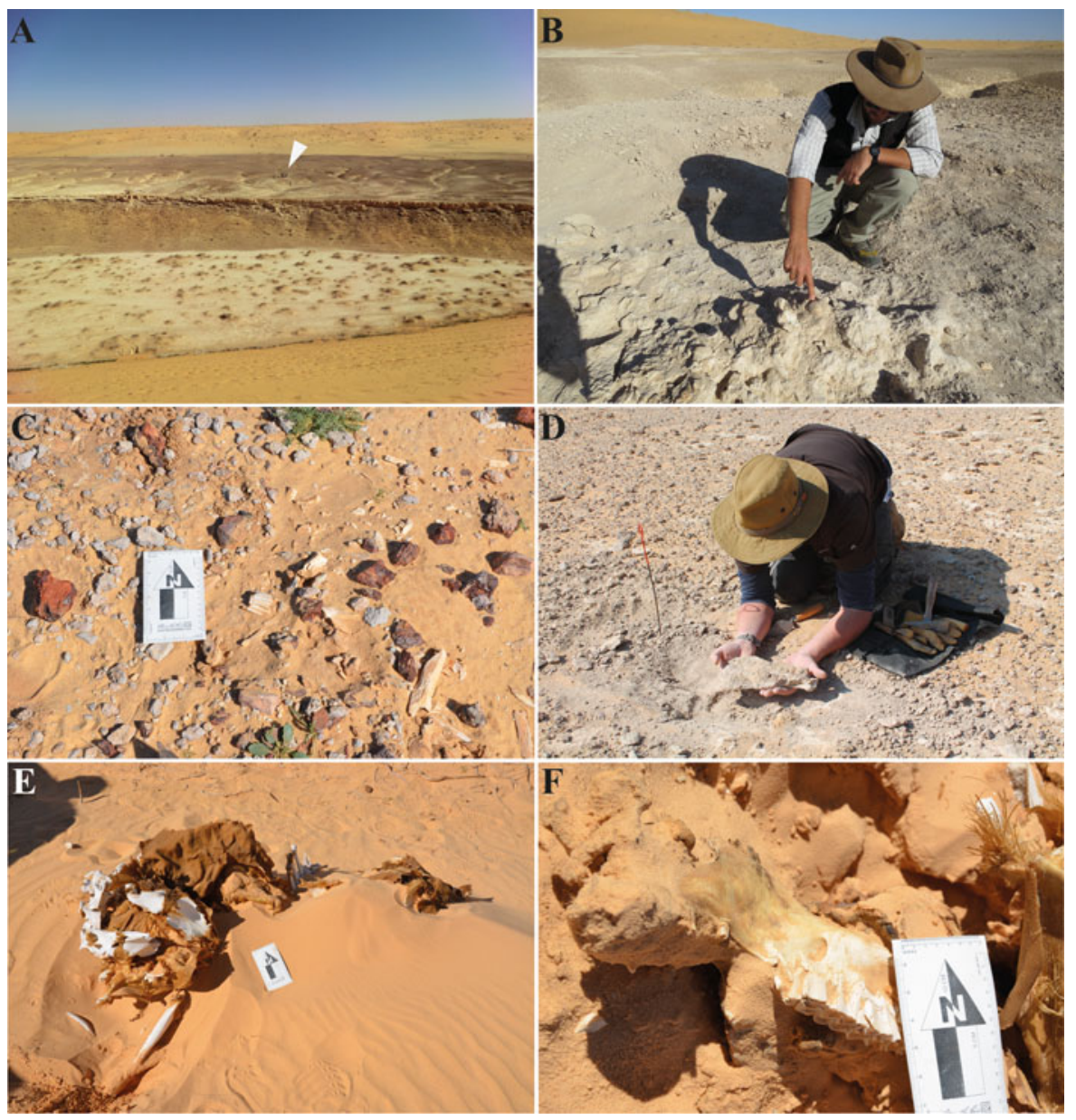

Figure 9. (color online) Landscape images of the sites, fossils, and modern bone accumulations. (A) Image of the Site 16.3 palaeolake with researchers (white arrow) indicating the location of the Syncerus skeleton; (B) Syncerus skeleton eroding out of the Site 16.3 palaeolake sediments; (C) lithic artefacts and probable Syncerus skeleton at site WNEF16_1; (D) medium-sized bovid scapula found eroding out of the surface of the KAM-4 NW lake; (E-F) modern camel carcass exhibiting varying stages of preservation and weathering.

unit that were not recognised by Rosenberg et al. (2013), perhaps because they were only preserved in some sections of the site. These consisted of silty sediments capped by a sandstone-like sandy marl and are interpreted as representing the final desiccation phase of the lake, meaning that the sequence records an entire dry-wet-dry cycle. The recovery of fossils from areas where the sandstone had eroded suggests that bones were deposited as the lake was drying. Most fossils were found on the surface of the palaeolake and concentrated in the southern half of the deposit, while at the centre of the palaeolake a single Syncerus skeleton was found eroding out of the surface of the palaeolake sediment (Fig. 9A and B).

The Site 16.3 fossil assemblage is the largest assemblage investigated here, with 615 fossils recovered representing six taxa, although the Site 16.3 lake is comparatively large and a non-insignificant number of these fossils can be attributed to a single large bovid. Small vertebrates are again rare, and although medium-sized mammals are most abundant, only a single horn core tentatively attributed to Oryx could be more precisely identified. Large-sized mammals are abundant and include Hippopotamus amphibius (NISP = 23, MNI =2) and Syncerus sp. cf. S. antiquus $(\mathrm{NISP}=53, \mathrm{MNI}=1)$. A dense concentration of Syncerus and unidentifiable bone fragments $(n=90)$ was recovered from an area of $\sim 3 \mathrm{~m}^{2}$ at the centre of the palaeolake exposure and, given their propinquity and similar appearance and preservation, are interpreted as a single Syncerus skeleton.

Fossils range from pale yellow to brown, and most specimens exhibit pitting, rounding, and polish consistent with wind abrasion (e.g., Fig. 8H). Some fossils retain sandstone cemented to their surface, consistent with the hypothesis that the fossils eroded from the uppermost sandstone unit preserved in some sections of the site. Manganese staining (e.g., Fig. 6D) and root etching were occasionally observed, with some instances of the latter being shallow and differing in colour from the surrounding bone (e.g., Fig. 8H), indicating that etching occurred more recently and probably following fossilisation (Fernández-Jalvo and Andrews, 2016). Fossils show weathering stages $0-4$, with stages 2 and 3 being most common $(n=172,63 \%)$ and, as at KAM-4 NW lake, there is a positive correlation between specimen size (length) and weathering (Spearman's rho, $r_{\mathrm{s}}=0.227, P<0.001$ ). 
Thirty-nine elements $(6.3 \%)$ show evidence for carnivore gnawing, including 28 measurable tooth pits with major and minor axes ranging from $1.6 \mathrm{~mm}$ to $9.7 \mathrm{~mm}$ and $1.5 \mathrm{~mm}$ to $7.0 \mathrm{~mm}$, respectively (Supplementary Table S10). Two tooth pits on epiphyseal and diaphyseal fragments measured $7.7 \times 7.0 \mathrm{~mm}$ and $7.5 \times 6.7 \mathrm{~mm}$, respectively, being most consistent with gnawing by a large carnivore such hyena or lion (cf. Delaney-Rivera et al., 2009). Appendicular elements are abundant $(\mathrm{n}=$ $64,43 \%$ of NISP), as too are carpals/tarsals $(\mathrm{n}=21$, $14 \%$ of NISP), and fragile vertebrae $(\mathrm{n}=21,14 \%$ of NISP) and ribs ( $\mathrm{n}=17,11 \%$ of NISP). Most long bones retain less than half their original circumference $(n=17$, $65 \%$ ) and exhibit fracture patterns consistent with dry fracturing $(\mathrm{n}=16,62 \%)$. Abundant easily transported elements (Voorhies groups I and II) and the low tooth to vertebrae ratio $(T / V=0.0)$ suggest that the assemblage may have undergone some hydraulic winnowing.

\section{WNEF16_1}

Similar to the individual Syncerus skeleton recovered at Site 16.3, the WNEF16_1 assemblage comprises a single large buffalo skeleton-provisionally attributed to Synceruseroding out of the palaeolake surface in a dense $1-\mathrm{m}^{2}$ concentration. While the bulk of the assemblage consists of unidentifiable bone fragments, most appear to be from a large animal, are similar in preservation and appearance, and are interpreted as representing a single individual. Fossils are sandy in colour and exhibit occasional superficial root etching. Interestingly, the WNEF16_1 assemblage exhibits the full spectrum of weathering stages, with most falling into stages 2 and $3(n=146,83 \%)$, and demonstrates, rather importantly, that significant variations in weathering can occur across very small spatial and temporal scales. Again, there is a positive correlation between specimen length and weathering (Spearman's rho, $r_{\mathrm{s}}=0.311, P<0.001$ ). The assemblage is very heavily fragmented, with almost the entire assemblage comprising small midshaft $(\mathrm{n}=91,43 \%$ of NRSP) and unidentifiable ( $\mathrm{n}=111,53 \%$ of NRSP $)$ bone fragments. All long bones have been fragmented such that they retain less than half their circumference $(n=91,100 \%)$, and most display fracture angle, outline, and edge characteristic consistent with dry fracturing $(n=42,67 \%)$.

\section{DISCUSSION}

\section{Species representation and palaeoenvironmental implications}

This study represents the first widespread taphonomic study of fossil faunal assemblages in the Arabian Peninsula and an important initial step in elucidating the processes governing fossil preservation and site formation in this unique region. Overall, the fauna identified here are comparable to other Pleistocene sites in the western Nefud Desert and include three previously unrecognised taxa in the Arabian Pleistocene fossil record-Nesokia sp., Muridae sp., and Hippotragus sp. The fauna from sites KAM-1 and Site 16.3, notably Hippopotamus, Equus, and Syncerus, is consistent with palaeoenvironmental data that demonstrate that at times during Marine Isotope Stage 5 (MIS 5; ca. 130-74 ka) the western Nefud Desert was significantly more humid, with expansive grasslands and interdunal lakes (e.g., Rosenberg et al., 2013; Jennings et al., 2015; Breeze et al., 2016; Groucutt et al., 2018). The presence of Hippopotamus and elephant at KAM-4 NW lake suggests a similar environmental scenario. While less can be reliably said about the other sites, the small sample sizes and lack of chronological data, the presence of taxa such as Hippotragus sp. (as at WNEF16_25), and the accompanying palaeolake sediments and taphonomic evidence (see next section of this Discussion) all suggest that these assemblages were deposited under conditions more humid than characterize the region today.

Overall, small vertebrates are drastically underrepresented in the Arabian fossil record. Even today, the hyperarid Nefud Desert is host to an array of small birds, reptiles, rodents, lagomorphs, and carnivores (see Harrison and Bates, 1991), and greater precipitation and grassland availability during interglaciations (i.e., an increase in primary productivity) would have only increased small animal species richness and abundance (the "energy-richness hypothesis"; Hawkins et al., 2003). The scarcity of small animal remains may reflect a sampling bias against smaller and more difficult to spot fossils during pedestrian surveys and is, in part, supported by the more abundant and diverse small animal assemblages in the excavated portion of the KAM- 4 NW lake assemblage, as well as at the nearby sites of $\mathrm{Al} \mathrm{Wusta} \mathrm{(Grou-}$ cutt et al., 2018) and Ti's al Ghadah (Stimpson et al., 2016; Stewart et al., 2019a). Alternatively, this bias might be the result of taphonomic processes that preferentially destroy smaller bones, and other researchers have noted that small animals have a reduced chance of being preserved in the fossil record (Behrensmeyer and Dechant Boaz, 1980; Haynes, 1988; Andrews, 1990). Moreover, while microfauna (small mammals, birds, and reptiles) may be accumulated by large carnivores (e.g., Kruuk, 1976; Williams et al., 2018), they are more typically accumulated by smaller mammals and raptors (Fernández-Jalvo et al., 2016) and, as such, have vastly different taphonomic histories. The small sample size in the present study precludes any detailed analysis, but future studies may elucidate the accumulation processes of microfauna in lakeside environments in Arabia.

Medium-sized bovids dominate the Arabian Pleistocene fossil record, and to date, remains of Oryx, Hippotragus, and Alcelaphinae have been identified (McClure, 1984; Stimpson et al., 2016; Groucutt et al., 2018; Stewart et al., 2019a). Oryx is particularly well represented in the Arabian Pleistocene fossil record, and analysis of the morphometry and morphology of some of these remains suggest that they may represent a now-extinct species, as has been alluded to for the remains recovered from the middle Pleistocene site of 
Ti's al Ghadah (Thomas et al., 1998; Stimpson et al., 2016). Large-sized animals include Syncerus, Hippopotamus amphibius, and elephant, and these taxa have been identified at other nearby sites (Stimpson et al., 2016; Groucutt et al., 2018), as well as farther south (McClure, 1984). Hippopotamus is relatively common in the Arabian fossil record, perhaps reflecting the research focus on palaeolake deposits.

\section{Taphonomic analysis}

The taphonomic study of the fossils also provided some key insights into the environmental and depositional histories of the assemblages. The dark brown/maroon colouration of some of the assemblages (as at KAM-4 NW lake; Fig. 4A) is indicative of deposition in oxygenated and biologically active soils, while manganese staining commonly reflects deposition in water or water-lain sediments and is consistent with the lacustrine setting in which the fossils were recovered (e.g., Fernández-Jalvo and Andrews, 2016; Fig. 8G). Root etching was occasionally observed and, in some instances, was deep and similar in appearance to the cortical bone, suggesting that etching occurred before fossilisation. In contrast, some root marks (as at WNEF16_1 and Site 16.3) were more surficial and differed in colour from the surrounding fossil bone, indicating etching occurred more recently (FernándezJalvo and Andrews, 2016; Fig. 8H). The latter is interesting in that it suggests that fossils remained near the surface during subsequent humid phases, probably facilitated by slow sedimentation rates and deflation during more arid intervals.

The varied weathering pattern observed at large and taxonomically diverse sites such as KAM-4 NW lake and Site 16.3 probably reflects attritional bone accumulations in which carcasses were continually added to the landscape. Lakes are attractive features in semiarid settings and provide a constant input of bones variably affected by weathering processes through time (Behrensmeyer, 1978; Haynes, 1988). Interestingly, the single Syncerus skeleton at WNEF16_1 exhibits the full spectrum of weathering stages, demonstrating that significant variations in weathering can occur across very small spatial and temporal scales. During our surveys, we also observed a camel carcass that, in a single cranium, was partially fleshed below the surface of the sand but exhibited stage 2 weathering above (Fig. 9C and D). Andrews and Whybrow (2005) also observed this, albeit not to the extent reported here, when monitoring a single camel carcass in a desert environment over a 15-year period; the authors attributed this to shifting sands covering and protecting small bones such as ribs and vertebrae. Likewise, smaller fossils are less weathered in some of the sites analysed here, although this is may be due to other factors preferentially protecting smaller bones (e.g., vegetation, lake water). While poor preservation and extensive wind abrasion make commenting on the duration of exposure problematic, we note that the scarcity of unweathered bone suggests that burial was typically slow or that bones were regularly re-exposed before fossilisation.
Wind abrasion is perhaps the most significant process affecting the Arabian surface fossil deposits and is known to be particularly prevalent in desert regions where there is abundant sandy substrate and little in terms of vegetation to stabilise sediments (Fernández-Jalvo and Andrews, 2016). The KAM-1 and KAM-4 fossil assemblages are most significantly impacted by wind abrasion, with all fossils showing some degree of rounding, pitting, and/or polish consistent with abrasion by windblown sand. While the extent of wind abrasion probably largely reflects time since exhumation, the position in the landscape relative to the surrounding dunes may also play a role, with dunes acting as either wind funnels or protective barriers. It is also possible that wind has spatially redistributed fossils in the landscape. Indeed, observations in a similar desert environment (Fuego-Patagonia) found strong winds significantly redistributed lithic artefacts in the landscape, many of which exceeded the size and weight of fossils reported here (Borrazzo, 2016). Such a process could explain the contrast between the densely concentrated Syncerus skeleton and the sparsely concentrated loose surface fossils at Site 16.3 (Figs. 3 and 9B).

Carnivores probably also played a role in distributing bones across the landscape, and despite the paucity of carnivore remains in the present study, their presence is inferred from tooth-marked bone (e.g., Fig. 8B). Large tooth pits, tooth notches, and green-fractured bones attest to the role of large bone crushing carnivores, such as hyena, in the accumulation of at least some of these assemblages (KAM-4, Site 16.3). That said, tooth-marked specimens are typically very rare and/or assemblages too small to provide more detailed insights into the role of carnivores as bone accumulators. The individual Syncerus skeleton from Site 16.3 does, however, appear to have been primarily accumulated by large carnivores, as suggested by gnawed ribs, epiphyses, and midshaft fragments. The scarcity of carnivore tooth marks here may be due to the various aforementioned attritional processes and greater evidence for carnivore processing at the well-preserved site of Ti's al Ghadah (Stewart et al., 2019a) lends some credence to this hypothesis.

Overall, skeletal part representation is poor, and unidentifiable fragments dominate across all assemblages (making up two-thirds of all material analysed here), followed by midshaft fragments, and small compact bones. The predominance of dense elements suggests that these assemblages have undergone significant density-mediated attrition, although the primary taphonomic process controlling for this remains difficult to assess. The scarcity of dense dental remains in the Arabian fossil deposits is at odds with this, but Behrensmeyer (1978) noted teeth in the Amboseli National Park, Kenya, rapidly disintegrated as a result of surface desiccation (see also Conard et al., 2008). Such a process may explain the scarcity of dental remains in the Nefud Desert fossil assemblages and is perhaps best exemplified at WNEF16_1, where, except for a single complete molar, dental remains are represented by heavily fragmented and fragile enamel 
and dentine splinters. The KAM-4 NW lake and Site 16.3 assemblages appear to have been less influenced by densitymediated attrition, as evidenced by abundant ribs, vertebrae, and small fragile animal remains. Overall, the results suggest that while density-mediated attrition was probably significant, it may not fully explain the taxonomic and skeletal part representation across all sites.

The clear bias towards easily transported elements and low tooth-to-vertebrae ratios suggest that some of the assemblages may have been influenced by hydraulic winnowing, perhaps as a result of lake-level fluctuations. Indeed, previous studies at KAM-1 found that the lake underwent frequent lake-level fluctuations (Rosenberg et al., 2013) and preliminary analysis of the KAM-4 NW lake sediments have identified fossil-bearing units ( $3 \mathrm{a}, 3 \mathrm{~b}$, and $4 \mathrm{~b}$; Fig. 2) with abundant allogenic sands, low relative $\mathrm{CaCO}_{3}$, and "rip up" marls (i.e., eroded and reworked marl fragments) indicative of a dynamic lake system. However, as highlighted earlier, the low number of teeth at these sites may also be explained by the preferential destruction of dental remains in lacustrine settings, and the values reported here are similar to those for nontransported bone assemblages from lake margin habitats in the Amboseli National Park, Kenya (Behrensmeyer and Dechant Boaz, 1980). While changes in local landscape hydrology are likely to have altered bone accumulations in some form, their specific influence is not currently discernible.

Bone breakage is ubiquitous, and most long bones retain less than half of their original circumference and exhibit fracture patterns consistent with dry fracturing. The KAM-1 assemblage is unique in having more complete long bones, which may reflect the more resilient bones of the larger animals preserved at the site (Hippopotamus, Syncerus). Bone fragmentation may have also been promoted by the physiochemical stresses associated with repeated temperature and moisture fluctuations, which are known to accelerate bone degradation and weathering (Behrensmeyer, 1978; Haynes, 1988; Pokines et al., 2018), and it has been argued that the poor preservation of fossil assemblages within the South African interior is the result of bone deposition within river, lake, and spring margins (Hutson, 2018). Dense, highly mineralised fossils, such as fossil teeth, have been found to be disproportionately affected by drastic temperature fluctuations, leading to their underrepresentation in some fossil assemblages (Conard et al., 2008).

More recently, fragmentation may have been exacerbated by insolation and salt weathering of fossils, processes particularly pronounced in desert environments and thought to be the source of much of the fragmentary geological material that fills the Nefud Desert today (Edgell, 2006). The former involves the differential expansion and contraction of rock constituents brought on by extreme diurnal temperature variations (Gutiérrez, 2005), whereas the latter involves the precipitation and expansion of salt crystals within rock cracks (Cooke and Smalley, 1968; Cooke, 1981). Palaeolakes in the Nefud Desert contain abundant carbonates and sulphates (Groucutt et al., 2018; see also Fig. 4K), and salt crystals were identified in the WNEF16_25 horn core that was found fragmented but retaining its shape in the landscape (Fig. 4J). Bauer (1988, p. 45) noted that animal teeth from caves in northeast Saudi Arabia were "split and crumbling" due to the formation of gypsum crystals within the lamellar bone. Mehlman (1987) went as far to suggest that salt weathering may be the most significant factor driving the breakdown of fossil material at Lake Eyasi in East Africa.

Finally, there are several instances of plastic deformation, and similar observations were made nearby at the site of $\mathrm{Al}$ Wusta (Groucutt et al., 2018). This could be the result of significant lake sediment buildup or dune migration over the sites. The latter is supported by the discovery of buried or partially buried palaeolakes beneath the present-day sand dunes (Schulz and Whitney, 1986; Breeze et al., 2017), while the varying positions of lakes at KAM-4 also suggest that the dune topography shifted substantially between phases of lake formation. Taken together, processes such as salt weathering, insolation weathering, and plastic deformation appear to have significantly modified the Arabian fossil assemblage appearance and composition and are likely to continue to do so into the future.

\section{CONCLUSIONS}

The fauna identified in this study strongly support the idea that at times during the Pleistocene, the western Nefud Desert boasted large grasslands and permanent river and lake systems. Notable is the presence of Hippopotamus, Syncerus, and elephants at several noncontemporaneous sites in the Nefud Desert (Thomas et al., 1998; Stimpson et al., 2016; Groucutt et al., 2018) and elsewhere in Arabia (McClure, 1984), demonstrating that pluvial phases were periodically wet and vegetated enough to allow for the dispersal of large water-dependent taxa into the Arabian interior. Climatic amelioration also facilitated the dispersal of hominins (Groucutt and Petraglia, 2012) and large carnivores (Stimpson et al., 2016; Stewart et al., 2019a, 2019b) into Arabia, with the presence of the latter inferred here from tooth-marked bone. While the role that carnivores played in the accumulation and modification of the Arabian fossil deposits remains difficult to assess, it seems likely it was greater than the current observations suggest. The same seems likely for hominins, given the extensive Arabian archaeological record (Groucutt and Petraglia, 2012) and likely evidence for carcass processing by hominins at the well-preserved site of Ti's al Ghadah (Roberts et al., 2018; Stewart et al., 2019a).

The sedimentological and taphonomic data also indicate that bones were deposited in conditions more humid than characterize the region today. Most striking about the Arabian fossil assemblages is their significant attrition, obscuring and fragmenting most finds. Fragmentation of bone may have been further exacerbated by the physiochemical stresses associated with lacustrine environments, principally repeated wetting and drying events. Perhaps even more significant in the assemblages studied here are post-exhumation processes 
such as wind abrasion, insolation, and salt weathering. Studies in hyperarid environments such as Arabia and the Sahara are further confounded by rapid sediment deflation and depositional hiatuses that promote the mixing of temporally discrete deposits. Indeed, the lack of evidence of butchery in assemblages with tightly associated fossils and lithic artefacts (as at WNEF16_1) suggests that there may not be an immediate temporal correlation between spatially associated objects. While more work is needed to investigate the impact of desertic processes on fossils, the fossils examined here clearly demonstrate that these processes are highly destructive and have drastically altered fossil appearance and assemblage composition.

\section{ACKNOWLEDGMENTS}

We thank Curtis Marean, Robin Dennell, Peter Andrews, and two anonymous reviewers for their comments on this paper. The Palaeodeserts Project thanks His Royal Highness Prince Sultan bin Salman, former president of the Saudi Commission for Tourism and National Heritage (SCTH), and the vice presidents, Ali Ghabban and Jamal Omar, for supporting our fieldwork in Saudi Arabia. We also thank Abdullah Al Zahrani and Abdulaziz al Omari of the SCTH for logistical assistance and advice. President of the Saudi Geological Survey Hussain. M. Otaibi, past president Zohair A. Nawab, and vice president Saleh El-Sefrey for providing research logistics. We thank the Saudi Geological Survey team for their help in the field: Abdulah Memesh, Ammar Abdulshakoor, Adel Matari, Ahmed Bahameem, and Abdou Al-Massari. We acknowledge the generous financial support of the SCTH, the Max Planck Society, the European Research Council (Advanced Grant to MDP, 295719 PALAEODESERTS: Climate Change and Hominin Evolution in the Arabian Desert: Life and Death at the crossroads of the Old World), and the Leverhulme Trust (PG-2017-087). HSG thanks the British Academy for funding. PSB acknowledges funding from the Leverhulme Foundation. MS would like to that the PANGEA Research Centre for funding. JL's research is supported by the Australian Research Council (ARC) Future Fellowship Grant (FT160100450).

\section{SUPPLEMENTARY MATERIAL}

The supplementary material for this article can be found at https:// doi.org/10.1017/qua.2020.6.

\section{REFERENCES}

Alberdi, M.T., Palombo, M.R., 2013. The late early to early middle Pleistocene stenonoid horses from Italy. Quaternary International 288, 25-44.

Andrews, P., 1990. Small mammal taphonomy. In: Lindsay, E.H., Fahlbusch, V., Mein, P. (Eds.), European Neogene Mammal Chronology. NATO ASI Series, Series A: Life Sciences 180. Springer, Boston, pp. 487-494.

Andrews, P., Whybrow, P., 2005. Taphonomic observations on a camel skeleton in a desert environment in Abu Dhabi. Palaeontologia Electronica 8(1).
Bauer, K., 1988. Noteworthy mammal records from the Summan Plateau/NE Saudi Arabia. Annalen des Naturhistorischen Museums in Wien, Series B 90, 43-50.

Behrensmeyer, A.K., 1975. Taphonomy and paleoecology in the hominid fossil record. Yearbook of Physical Anthropology 19, 36-50.

Behrensmeyer, A.K., 1978. Taphonomic and ecological information from bone weathering. Paleobiology 4, 150-162.

Behrensmeyer, A.K., Dechant Boaz, D.E., 1980. The recent bones of Amboseli Park, Kenya in relation to East African paleoecology. In: Behrensmeyer, A.K., Hill, A. (Eds.), Fossils in the Making. University of Chicago Press, Chicago, pp. 72-93.

Bibi, F., Hill, A., Beech, M., Yasin, W., 2013 Late Miocene fossils from the Baynunah Formation, United Arab Emirates: summary of a decade of new work. In: Wang, X., Flynn, L.J., Fortelius, M., (Eds.), Fossil Mammals of Asia: Neogene Biostratigraphy and Chronology. Columbia University Press, New York, pp. 583-594.

Binford, L.R., 1981. Bones: Ancient Men and Modern Myths. Academic Press, New York.

Blinkhorn, J., Achyuthan, H., Petraglia, M.D., 2015. Ostrich expansion into India during the late Pleistocene: implications for continental dispersal corridors. Palaeogeography, Palaeoclimatology, Palaeoecology 417, 80-90.

Blumenschine, R.J., 1986. Carcass consumption sequences and the archaeological distinction of scavenging and hunting. Journal of Human Evolution 15, 639-659.

Blumenschine, R.J., 1988. An experimental model of the timing of hominin and carnivore influence on archaeological bone assemblages. Journal of Archaeological Science 15, 483-502.

Blumenschine, R.J., 1989. A landscape taphonomic model of the scale of prehistoric scavenging opportunities. Journal of Human Evolution 18, 345-371.

Borrazzo, K., 2016. Lithic taphonomy in desert environments: contributions from Fuego-Patagonia (Southern South America). Quaternary International 15, 19-28.

Breeze, P.S., Drake, N.A., Groucutt, H.S., Parton, A., Jennings, R.P., White, T.S., Clark-Balzan, L., et al. 2015. Remote sensing and GIS techniques for reconstructing Arabian palaeohydrology and identifying archaeological sites. Quaternary International 382, 98-119.

Breeze, P.S., Groucutt, H.S., Drake, N.A., Louys, J., Scerri, E.M.L., Armitage, S.J., Zalmout, I.S.A., et al., 2017. Prehistory and palaeoenvironments of the western Nefud Desert, Saudi Arabia. Archaeological Research in Asia 10, 1-16.

Breeze, P.S., Groucutt, H.S., Drake, N.A., White, T.S., Jennings, R.P., Petraglia, M.D., 2016. Palaeohydrological corridors for hominin dispersals in the Middle East 250-70,000 years ago. Quaternary Science Reviews 144, 155-185.

Bunn, H.T., 1982. Meat-Eating and Human Evolution: Studies on the Diet and Subsistence Patterns of Plio-Pleistocene Hominids in East Africa. Ph.D. dissertation, University of California, Berkeley.

Bunn, H.T., Kroll, E.M., 1986. Systematic butchery by Plio/Pleistocene hominids at Olduvai Gorge, Tanzania. Current Anthropology 27, 437-452.

Clark, J.L., 2019. The Still Bay and pre-Still Bay fauna from Sibudu Cave: taphonomic and taxonomic analysis of the micromammal remains from the Wadley Excavations. Journal of Paleolithic Archaeology 2, 26-73.

Conard, N.J., Walker, S.J., Kandel, A.W., 2008. How heating and cooling and wetting and drying can destroy dense faunal elements and lead to differential preservation. Palaeogeography, Palaeoclimatology, Palaeoecology 226, 236-245. 
Cooke, R.U., 1981. Salt weathering in deserts. Proceedings of the Geologists' Association 92, 1-16.

Cooke, R.U., Smalley, I.J., 1968. Salt weathering in deserts. Nature 220, 1226-1227.

Delagnes, A., Tribolo, C., Bertran, P., Brenet, M., Crassard, R., Jaubert, J., Khalidi, L., et al., 2012. Inland human settlement in southern Arabia 55,000 years ago. New evidence from the Wadi Surdud Middle Paleolithic site complex, western Yemen. Journal of Human Evolution 63, 452-474.

Delaney-Rivera, C., Plummer, T.W., Hodgson, J.A., Forrest, F., Hertel, F., Oliver, J.S., 2009. Pits and pitfalls: taxonomic variability and patterning in tooth mark dimensions. Journal of Archaeological Science 36, 2597-2608.

Denys, C., Schuster, M., Guy, F., Mouchelin, G., Vignaud, P., Viriot, L., Brunt, M., et al., 2007. Taphonomy in present day desertic environment: the case of the Djourab (Chad) PlioPleistocene deposits. Journal of Taphonomy 5, 177-203.

Domínguez-Rodrigo, M., 2001. A study of competition in riparian and open habitats of modern savannas and its implications for hominid behavioral modelling. Journal of Human Evolution 40, 77-98.

Domínguez-Rodrigo, M., Piqueras, A., 2003. The use of tooth pits to identify carnivore taxa in tooth-marked archaeofaunas and their relevance to reconstruct hominid carcass processing behaviours. Journal of Archaeological Science 30, 1385-1391.

Drake, N.A., Breeze, P., Parker, A., 2013. Palaeoclimate in the Saharan and Arabian Deserts during the Middle Palaeolithic and the potential for hominin dispersals. Quaternary International 300, 48-61.

Driesch, A. von den, 1976. A Guide to the Measurement of Animal Bones from Archaeological Sites. Peabody Museum Press, Harvard University.

Edgell, H.S., 2006. Arabian Deserts: Nature, Origin and Evolution. Springer, Dordrecht, Netherlands.

Faith, J.T., 2007. Sources of variation in carnivore tooth-mark frequencies in a modern spotted hyena (Crocuta crocuta) den assemblage, Amboseli Park, Kenya. Journal of Archaeological Science 34, 1601-1609.

Faith, J.T., Behrensmeyer, A.K., 2006. Changing patterns of carnivore modification in a landscape bone assemblage, Amboseli Park, Kenya. Journal of Archaeological Science 33, 1718-1733.

Fernández-Jalvo, Y., Andrews, P., 2003. Taphonomic effects of water abrasion on bone fragments. Journal of Taphonomy 1, 417-163.

Fernández-Jalvo, Y., Andrews, P., 2016. Atlas of Taphonomic Identifications. Springer, Dordrecht, Netherlands.

Fernández-Jalvo, Y., Andrews, P., Denys, C., Sesé, C., Stoetzel, E., Marin-Monfort, D., Pesquero, D., 2016. Taphonomy for taxonomists: implications of predation in small mammal studies. Quaternary Science Reviews 139, 138-157.

Gentry, A.W., 1964. Skull characters of African gazelles. Annals and Magazine of Natural History 7(78), 353-382.

Gentry, A.W., 1967. Pelorovis oldowayensis Reck, an extinct bovid from East Africa. Bulletin of the British Museum (Natural History), Geology 14, 243-299.

Gentry, A.W., 2010. Bovidae. In: Werdelin, L., Sanders, W.J. (Eds.), Cenozoic Mammals of Africa. University of California Press, Berkeley, pp. 741-796.

Gentry, A.W, Gentry, A., 1978. Fossil Bovidae (Mammalia) of Olduvai Gorge, Tanzania. Part 1. Bulletin of the British Museum Natural History (Geology) 29, 290-446.

Groucutt, H.S., Grün, R., Zalmout, I.A.S., Drake, N.A., Armitage, S.J., Candy, I., Clark-Wilson, R., et al., 2018. Homo sapiens in Arabia by 85,000 years ago. Nature Ecology and Evolution 2, 1-10.
Groucutt, H.S., Petraglia, M.D., 2012. The preshistory of the Arabian Peninsula: deserts, dispersals, and demography. Evolutionary Anthropology 21, 113-125.

Groucutt, H.S., Shipton, C., Alsharekh, A., Jennings, R., Scerri, E.M.L., Petraglia, M.D., 2015a. Late Pleistocene lakeshore settlement in northern Arabia: Middle Palaeolithic technology from Jebel Katefeh, Jubbah. Quaternary International 24, 215-236.

Groucutt, H.S., White, T.S., Clark-Balzan, L., Parton, A., Crassard, R., Shipton, C., Jennings, R.P., et al., 2015b. Human occupation of the Arabian Empty Quarter during MIS 5: evidence from Mundafan Al-Buhayrah, Saudi Arabia. Quaternary Science Reviews $119,116-135$.

Gutiérrez, M., 2005. Climatic Geomorphology. Developments in Earth Surface Processes 8. Elsevier Science, Amsterdam.

Hammer, Ø., Harper, D.A.T., Ryan, P.D., 2001. PAST: palaeontological statistics software package for education and data analysis. Palaeontologica Electronica 4, 1-9.

Harrison, D.L., Bates, P.J.J., 1991. The Mammals of Arabia. Harrison Zoological Museum, Sevenoaks, UK.

Hawkins, B.A., Field, R., Cornell, H.V., Currie, D.J., Guégan, J.-F., Kaufman, D., Kerr, J.T., et al., 2003. Energy, water, and broad-scale geographic patterns of species richness. Ecology 84, 3105-3117.

Haynes, G., 1988. Mass deaths and serial predation: comparative taphonomic studies of modern large mammal death sites. Journal of Archaeological Science 15, 219-235.

Hooijer, D.A., 1950. The fossil Hippopotamidae of Asia, with notes on the recent species. Zoologische Verhandelingen 8, 1-123.

Hutson, J.M., 2018. The faunal remains from Bundu Farm and Pniel 6: examining the problematic Middle Stone Age archaeological record within the southern African interior. Quaternary International 466, 178-193.

Jennings, R.P., Singarayer, J., Stone, E.J., Krebs-Kanzow, U., Khon, V., Nisancioglu, K.H., Pfeiffer, M., et al., 2015. The greening of Arabia: multiple opportunities for human occupation of the Arabian Peninsula during the late Pleistocene inferred from an ensemble of climate model simulations. Quaternary International 382, 181-199.

Kruuk, H., 1976. Feeding and social behaviour of the striped hyaena (Hyaena vulgari Desmarest). East African Wildlife Journal 14, 91-111.

Lam, Y.M., Chen, X., Pearson, O.M., 1999. Intertaxonomic variability in patterns of bone density and the differential representation of bovid, cervid and equid elements in the archaeological record. American Antiquity 64, 343-362.

Marean, C.W., Domínguez-Rodrigo, M., Pickering, T.R., 2004. Skeletal element equifinality in zooarchaeology begins with methods: the evolution and status of the "shaft critique." Journal of Taphonomy 2, 69-98.

Martínez-Navarro, B., Pérez-Claro, J.A., Palombo, M.R., Rook, L., Palmqvist, P., 2007. The Olduvai buffalo Pelorovis and the origin of Bos. Quaternary Research 68, 220-226.

McClure, H.A., 1984. Late Quaternary Palaeoenvironments of the Rub' al Khali. Ph.D. Thesis, University College, London.

Mehlman, M.J., 1987. Provenience, age and associations of archaic Homo sapiens crania from Lake Eyasi, Tanzania. Journal of Archaeological Science 14, 133-162.

Olsen, S.L., Shipman, P., 1988. Surface modification on bone: trampling versus butchery. Journal of Archaeological Science 15, 535-553.

Parton, A., Clark-Balzan, L., Parker, A., Preston, G.W., Sung, W.W., Breeze, P.S., Leng, M.J., et al., 2018. Middle-late Quaternary palaeoclimate variability from lake and wetland deposits in the 
western Nefud Desert, Northern Arabia. Quaternary Science Reviews 202, 78-97.

Parton, A., White, T.S., Parker, A.G., Breeze, P.S., Jennings, R., Groucutt, H.S., Petraglia, M.D., 2015. Orbital-scale climate variability in Arabia as a potential motor for human dispersals. Quaternary International 382, 82-97.

Peters, J., 1986. Osteomorphological features of the appendicular skeleton of African buffalo, Syncerus caffer (Sparrman, 1779) and of domestic cattle, Bos primigenius f. taurus Bojanus, 1827. International Journal of Mammalian Biology 53, 108-123.

Petraglia, M.D., Alsharekh, A., Breeze, P., Clarkson, C., Crassard, R., Drake, N.A., Groucutt, H.S., et al.., 2012. Hominin dispersal into the Nefud Desert and Middle Palaeolithic settlement along the Jubbah Palaeolake, northern Arabia. PLoS ONE 7: e49840.

Petraglia, M.D., Alsharekh, A.M., Crassard, R., Drake, N.A., Groucutt, H.S., Parker, A.G., Roberts, R.G., 2011. Middle Paleolithic occupation on a marine isotope stage 5 lake-shore in the Nefud Desert, Saudi Arabia. Quaternary Science Reviews 50, $1555-1559$.

Pokines, J.T., Faillace, K., Berger, J., Pirtle, D., Sharpe, M., Curtis, A., Lombardi, K., Admans, J., 2018. The effects of repeated wet-dry cycles as a component of bone weathering. Journal of Archaeological Science: Reports 17, 433-441.

Potts, D., 2001. Ostrich distribution and exploitation in the Arabian Peninsula. Antiquity 75, 182-190.

Roberts, P., Stewart, M., Alagaili, A.N., Breeze, P., Candy, I., Drake, N., Groucutt, H.S., et al.., 2018. Fossil herbivore stable isotopes reveal middle Pleistocene hominin palaeoenvironment in "Green Arabia." Nature Ecology and Evolution 2, 1871-1878.

Rosenberg, T.M., Preusser, F., Fleitmann, D., Schwalb, A., Penkman, K., Schmid, T.W., Al-Shanti, M.A., Kadi, K., Matter, A., 2011. Humid periods in southern Arabia: windows of opportunity for modern human dispersal. Geology 39, 1115-1118.

Rosenberg, T.M., Preusser, F., Risberg, J., Plikk, A., Kadi, K.A., Matter, A., Fleitmann, D., 2013. Middle and Late Pleistocene humid periods recorded in palaeolake deposits of the Nafud desert, Saudi Arabia. Quaternary Science Reviews 70, 109-123.

RStudio Team, 2015. RStudio: Integrated Development for $R$. RStudio, Inc., Boston, MA. http://www.rstudio.com. Accesed 3 May 2019.

Scerri, E.M.L., Breeze, P.S., Parton, A., Groucutt, H.S., White, T.S., Stimpson, C., Clark-Balzan, L., Jennings, R., Alsharekh, A.M., Petraglia, M.D., 2015. Middle to Late Pleistocene human habitation in the western Nefud Desert, Saudi Arabia. Quaternary International 382, 200-214.

Schulz, E., Whitney, J., 1986. Upper Pleistocene and Holocene lakes in the An Nafud, Saudi Arabia. Hydrobiologia 143, 175-190.

Shani, A., Kumar, G., Bajpai, S., Srinivasan, S., 1989. Ultrastructure and taxonomy of ostrich eggshells from Upper Palaeolithic sites of India. Journal of the Palaeontological Society of India 34, 91-98.
Shipton, C., Blinkhorn, J., Breeze, P.S., Cutherbertson, P., Drake, N., Groucutt, H.S., Jennings, R.P., et al.., 2018. Acheulean technology and landscape use at Dawadmi, central Arabia. PLOS ONE 13, e0200497.

Shipton, C., Parton, A., Breeze, P., Jennings, R., Groucutt, H.S., White, T.S., Drake, N., Crassard, R., Alsharekh, A., Pertraglia, M.D., 2014. Large flake Acheulean in the Nefud Desert of northern Arabian. PalaeoAnthropology 2014, 446-462.

Stewart, M., Louys, J., Groucutt, H.S., Candy, I., Clark-Wilson, R., Breeze, P.S., Drake, N.A., et al., 2019a. Taphonomic and zooarchaeological investigations at the middle Pleistocene site of Ti's al Ghadah, western Nefud Desert, Saudi Arabia. Quaternary Science Reviews 218, 228-253.

Stewart, M., Louys, J., Price, G.J., Drake, N.A., Groucutt, H.S., Petraglia, M.D., 2019b. Middle and Late Pleistocene mammal fossils of Arabia and surrounding regions: implications for biogeography and hominin dispersals. Quaternary International 515, 12-29.

Stimpson, C.M., Breeze, P.S., Clark-Balzan, L., Groucutt, H.S., Jennings, R., Parton, A., Scerri, E.M.L., White, T.S., Petraglia, M.D., 2015. Stratified Pleistocene vertebrates with a new record of a jaguar-sized pantherine (Panthera cf. gombaszogensis) from northern Saudi Arabia. Quaternary International 383, 168-180.

Stimpson, C.M., Lister, A., Parton, A., Clark-Balzan, L., Breeze, P.S., Drake, N.A., Groucutt, H.S., et al., 2016. Middle Pleistocene vertebrate fossils from the Nefud Desert, Saudi Arabia. Quaternary Science Reviews 143, 13-36.

Texier, P., Porraz, G., Parkington, J., Rigaud, J.-P., Poggenpoel, C., Tribolo, C., 2013. The context, form and significant of the MSA engraved ostrich eggshell collection from Diepkloof Rock Shelter, Western Cape, South Africa. Journal of Archaeological Science 40, 3412-3431.

Thomas, H., Geraads, D., Janjou, D., Vaslet, D., Memesh, A., Billiou, D., Bocherens, H., et al.., 1998. First Pleistocene faunas from the Arabian peninsula: an Nafud Desert, Saudi Arabia. Comptes Rendus de l'Académie des Sciences, Series IIA, Earth and Planetary Science 326, 145-152.

Thomas, H., Sen, S., Khan, M., Battail, B., Ligabues, G., 1982. The Lower Miocene fauna of Al-Sarrar (Eastern Province, Saudi Arabia). ATLAL. Journal of Saudi Arabian Arcaheology 5, 109-136.

Villa, P., Mahieu, E., 1991. Breakage pattern of human long bones. Journal of Human Evolution 21, 27-48.

Voorhies, M.R., 1969. Taphonomy and population dynamics of an Early Pliocene fauna, Knox County, Nebraska. University of Wyoming Contributions to Geology, Special Paper 1, 1-69.

Williams, J., Andrews, P., García-Morato, S., Villa, P., FernándezJalvo, 2018. Hyena as a predator of small mammal? Taphonomic analysis from the site of Bois Roche, France. Paleobiology 44, 511-529.

Whybrow, P.J., Hill, A., 1999. Fossil Vertebrates of Arabia: With Emphasis on the Late Miocene Faunas, Geology, and Palaeoenvironments of the Emirate of Abu Dhabi, United Arab Emirates. Yale University Press, New Haven, CT. 